\title{
Flexible home care scheduling
}

\author{
Federico Mosquera ${ }^{\mathrm{a}, *}$, Pieter Smet ${ }^{\mathrm{a}}$, Greet Vanden Berghe ${ }^{\mathrm{a}}$ \\ ${ }^{a} K U$ Leuven, Department of Computer Science, CODeS 83 imec-ITEC \\ Gebroeders De Smetstraat 1, 9000 Gent, Belgium
}

\begin{abstract}
Home care services are in high demand given how they are steadily becoming the primary source of care for the elderly. Powerful decision support tools are indispensable for effectively managing available staff in the context of ever-increasing demand for care and limited caregiver availability. This paper advances home care literature by introducing flexible task durations, thereby enabling tasks to be completed faster and ultimately more care to be scheduled. This new concept, which originates from practice, introduces an additional decision to be made when creating a schedule, thereby greatly increasing the scheduling complexity. Consequently, this paper introduces a new optimization-based decision support model which allows for scheduling with flexible task duration, as well as other types of flexibility. A computational study quantifies the impact of: (i) scheduling with a finer task granularity thereby enabling accurate prioritization of high and low priority care, (ii) flexibility in task duration enabling tasks to be completed faster and more care to be scheduled, and (iii) increasing the number of different locations visited by a caregiver thereby enabling a trade-off between the number of serviced clients and caregiver workload. A new publicly available real-world data set is used, obtained directly from home care organizations operating in Flanders. Analysis of the computational results demonstrates that significant improvements in operational efficiency may be realized with minimal effort required by organizations. Furthermore, the proposed algorithm's performance is confirmed by comparison against the bounds obtained by solving an integer programming formulation of the problem. Finally, a management policy scheme is proposed which, when gradually implemented in a home care organization, results in a more efficient and therefore cost-effective deployment of its workforce.
\end{abstract}

Keywords: home care scheduling, controllable processing times, task

\footnotetext{
* Corresponding author

Email address: federico.mosquera@kuleuven.be (Federico Mosquera)
} 
disaggregation, heuristics, integer programming

\section{Introduction}

Due to an increasingly elderly population and a shift from residential care towards home care, the Flemish home care sector is approaching a complex and rapidly changing environment composed of highly diverse groups of clients with multifaceted and volatile care requirements. In 2015, the various home care organizations active in Flanders provided a total of 20.9 million hours of care to over 100,000 households, representing an increase of over $40 \%$ compared to 2005 (Research Center Flemish Government, 2015). The Flemish government is seeking to further establish home care as the primary source of care, thereby bringing care to individuals and not vice versa. This tendency is increasingly noticeable throughout Europe. In the last decade, European countries have witnessed, on average, an increase of $10 \%$ in persons aged 65 and over who receive long-term care at home (OECD Health Statistics, 2016). Proper workforce management thus represents a crucial aspect of future home care.

The increased demand for home care, combined with a growing scarcity of resources, results in a new situation in which decision support systems become indispensable when scheduling home care workers. The present paper introduces a rich decision support model which enables home care organizations to deploy their available resources more effectively through the use of optimization algorithms. The addressed operational decision problem concerns the assignment, scheduling and routing of caregivers such that the organizations' clients receive their requested care. These decisions are subject to a variety of operational constraints concerning both caregivers and clients, such as time windows, qualifications, labor legislation and personal preferences. In essence, home care scheduling is a multi-objective problem as each stakeholder considers different aspects of a solution to be important (Gregory et al., 2017). The organization's management, for example, might be primarily concerned with satisfying health and safety regulations, while a client may wish to be visited by his preferred caregiver as many times as possible. Moreover, the different objectives may be contradictory in nature, making it difficult to model and solve the problem (Castillo-Salazar et al., 2016).

The present research was motivated by Flemish home care organizations who realized that their current manual scheduling procedures are becoming inadequate in the context of increased complexity originating from the aforementioned challenges. Current practice in these organizations involves scheduling three- or four-hour blocks of unspecified services either in the morning or in the afternoon, as illustrated in Figure 1(a). This approach is henceforth referred to as scheduling with aggregated 
tasks, given that this type of planning is not concerned with scheduling individual home care tasks.

However, as client contracts are becoming more and more detailed, there is a need to consider these individual tasks, taking into account their desired frequency, duration and priority. This approach is referred to as scheduling with disaggregated tasks, as illustrated in Figure 1(b). Evidently, creating a schedule based on individual tasks enables greater efficiency insofar as deploying available staff by, for example, shortening certain task durations or eliminating low-priority tasks altogether and instead outsourcing them to family members.

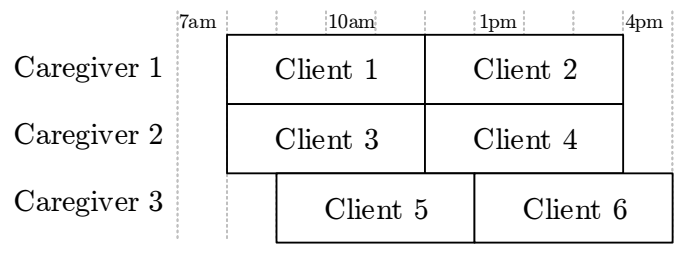

(a) Scheduling with aggregated tasks

\begin{tabular}{|c|c|c|c|c|c|c|c|c|c|}
\hline \multirow{3}{*}{ Caregiver 1} & \multirow[t]{3}{*}{$7 \mathrm{am}$} & \multicolumn{3}{|c|}{$10 \mathrm{am}$} & \multicolumn{4}{|c|}{$1 \mathrm{pm}$} & \multirow[t]{2}{*}{$4 \mathrm{pm}$} \\
\hline & & \multicolumn{3}{|c|}{ Client 1} & \multicolumn{4}{|c|}{ Client 2} & \\
\hline & & & $\mathrm{A}$ & $1 \mathrm{~B}$ & $2 \mathrm{~A}$ & & \begin{tabular}{l|l}
$2 \mathrm{~B}$ & $2 \mathrm{C}$ \\
\end{tabular} & $2 \mathrm{D}$ & \\
\hline \multirow[t]{2}{*}{ Caregiver 2} & & \multicolumn{3}{|c|}{ Client 3} & $\mathrm{C}$ & & \multicolumn{2}{|c|}{ Client 4} & \\
\hline & & $3 \mathrm{~A}$ & $3 \mathrm{~B}$ & $3 \mathrm{C}$ & $5 \mathrm{~A}$ & & $4 \mathrm{~A}$ & $4 \mathrm{~B}$ & \\
\hline \multirow[t]{2}{*}{ Caregiver 3} & & \multicolumn{3}{|c|}{ C 7} & C 8 & & C 6 & \multicolumn{2}{|c|}{ C 9} \\
\hline & & & \begin{tabular}{l|l}
$7 \mathrm{~A}$ \\
\end{tabular} & & $8 \mathrm{~A}$ & & $6 \mathrm{~A}$ & $9 \mathrm{~A}$ & $9 \mathrm{~B}$ \\
\hline
\end{tabular}

(b) Scheduling with disaggregated tasks

Figure 1: Examples of scheduling with aggregated and disaggregated tasks

Due to the significant number of individual tasks per client, it is impossible for human planners to create schedules with disaggregated tasks. However, from an organizational point-of-view, available resources will be better deployed, while from a client perspective, the delivered care will be better adjusted to their own personal needs. The proposed decision support model achieves these gains by emphasizing and exploiting flexible scheduling when solving the optimization problem.

Based on the novel elements in the proposed decision support model, four management policies are defined and computationally evaluated which, when implemented sequentially, enable an organization to gradually adjust their scheduling process from rigid to flexible.

The remainder of this paper is organized as follows. Section 2 presents a review of related scheduling problems from the academic literature and highlights the novel features of the proposed model. This section further clarifies the motivation behind the proposed model's emphasis on task and staff scheduling characteristics rather than the more commonly-encountered routing aspect. Section 3 formally defines the optimization problem. The proposed algorithm is introduced in Section 4. Section 5 analyzes a series of computational experiments which highlight the gains achievable with the proposed approach. A number of scenarios are investigated which further demonstrate the potential of the proposed decision support model. Section 
6 introduces four management policies which may be implemented to increase an organization's flexibility in staff scheduling. Finally, Section 7 concludes the paper and identifies directions for future research.

\section{Related work}

\subsection{Home health care scheduling}

Home care scheduling (HC) and home health care scheduling (HHC) constitute two separate problems, albeit the terminology is often employed interchangeably. Rendl et al. (2012) provide an account of this phenomenon. HHC concerns nurses traveling to patients' homes and providing medical services such as administering medicine or wound dressing. HC, on the other hand, concerns domestic services such as housekeeping or accompanying a client to social activities. While the difference may appear trivial at first, the nature of the activities has a major impact upon which constraints and objectives are relevant when optimizing a schedule.

Firstly, HC workers usually perform tasks which are, on average, more timeconsuming than HHC. As an example, an HC worker may spend four hours on household activities at a client's home, whereas an HHC task such as administering an injection takes only two or three minutes. Unsurprisingly, Holm and Angelsen (2014) report that $\mathrm{HHC}$ nurses spend up to $22 \%$ of their time traveling between patients. Minimizing travel time or distance is thus often the main objective in existing models for HHC scheduling (Liu et al., 2014; Maya Duque et al., 2015; Akjiratikarl et al., 2007). However, in HC, the number of clients visited per day per caregiver is far lower, for example, two in the schedule shown in Figure 1(a). Consequently, travel time is less important as an objective and the focus may shift towards objectives which have received little attention in operational research literature concerning HHC.

Secondly, due to the non-medical nature of HC tasks, flexibility may be exploited when scheduling with scarce resources. For example, if house cleaning ordinarily takes four hours, it is likely that the same task may be completed within three hours, albeit with somewhat poorer quality. Similarly, it is possible to reduce the number of times a task is scheduled during the scheduling period without incurring significant negative consequences for the client. Exploiting flexibility has been found to be common practice within the consulted home care organizations, but such flexibility is impossible for $\mathrm{HHC}$ due to its inherent medical nature. Despite the widespread occurrence of task flexibility in HC practice, this has yet to be accommodated within optimization models for HC scheduling.

There are, however, also strong similarities between HC and HHC. Most notably, both integrate routing, scheduling and assignment problems (Fikar and Hirsch, 
2016). Common model elements include time windows (Bertels and Fahle, 2006), personal preferences (Trautsamwieser and Hirsch, 2011) and qualifications (Nickel et al., 2012). The workers' contractual constraints are often also included in practical optimization models. These constraints include limitations on overtime (Lanzarone and Matta, 2014), breaks and idle time (Trautsamwieser and Hirsch, 2014) and number of consecutive days worked (Di Gaspero and Urli, 2014). However, due to the aforementioned reasons, these characteristics may be more easily accommodated by $\mathrm{HC}$ than HHC.

Finally, there are a number of additional common characteristics between $\mathrm{HC}$ and vehicle routing. Consistency considerations may appear in various forms, for example, a client may wish to be visited at the same time and day each week. Moreover, it is common for clients to prefer the same caregivers to visit them so as to establish a trusted relationship (Kovacs et al., 2014). Whenever an activity for a client is performed periodically, it is important to spread out the days on which the tasks are scheduled, referred to as the spreading of tasks by Begur et al. (1997).

Table 1 presents a comparative analysis of recent studies concerning automated $\mathrm{HC}$ and HHC scheduling in terms of problem characteristics. This analysis reveals that common characteristics include caregiver qualifications, time windows, caregiver/client preferences, continuity of care, caregiver idle time, multiple tasks per client and task rejection. Few papers focus on evenly distributing tasks throughout the scheduling period (spreading) or on fairness aspects regarding task assignment. To the best of our knowledge, the present paper constitutes the first piece of research to consider flexible task duration in the context of home care scheduling.

All the studies detailed in Table 1 consider some form of time windows, either as a hard constraint or as a term in the objective function. Similarly, caregiver qualifications and preferences, which are present in all models, are often employed to model requirements much like this study's, such as language proficiency, gender, smoking status and pet allergies. For example, Bredström and Rönnqvist (2008) model each staff member as having a set of skills such as knowledge of a specific language, medical certificate and gender preferences. Meanwhile, Hiermann et al. (2013) model gender preferences, smoking status and pet allergies.

Continuity of care refers to assigning the same caregiver to a patient for a sustained period of time (Lanzarone and Matta, 2014). This is a particularly important aspect when working with elderly people given that establishing and maintaining caregiver-patient relations typically increases the quality of delivered service. Note that in some cases a set of reference caregivers is employed when patient care requirements exceed, for example, two visits per week (Maya Duque et al., 2015).

Two approaches concerning fairness were found: (i) balance workload of em- 
ployees and (ii) fairness regarding task assignment for patients. First, Lanzarone and Matta (2014) and Mutingi and Mbohwa (2014) approach fairness by taking employee workloads into consideration. Lanzarone and Matta (2014) achieve this by taking into account the stochasticity concerning nurse schedules and patient demands by minimizing nurses' overtime. Mutingi and Mbohwa (2014) address fairness by maximizing workload balance among the assigned workers. Second, Mankowska et al. (2014) approach fairness by balancing the demand of all patients by way of minimizing the greatest tardiness among all services.

To summarize, this comparative analysis shows that many problem characteristics which are relevant in the literature are addressed by the model proposed in this paper. Furthermore, flexible task durations are introduced which, given the great potential for improving schedule quality, may have a significant impact on how schedules are created in home care organizations.

\begin{tabular}{|c|c|c|c|c|c|c|c|c|c|c|c|}
\hline Reference & $\begin{array}{l}\text { Caregiver } \\
\text { preferences }\end{array}$ & $\begin{array}{c}\text { Caregiver } \\
\text { qualifications }\end{array}$ & $\begin{array}{c}\text { Client } \\
\text { preferences }\end{array}$ & $\begin{array}{c}\text { Continuity } \\
\text { of care }\end{array}$ & Fairness & $\begin{array}{l}\text { Flexible } \\
\text { duration }\end{array}$ & $\begin{array}{l}\text { Idle } \\
\text { time }\end{array}$ & $\begin{array}{c}\text { Multiple } \\
\text { tasks }\end{array}$ & Spreading & $\begin{array}{c}\text { Task } \\
\text { rejection }\end{array}$ & $\begin{array}{c}\text { Time } \\
\text { windows }\end{array}$ \\
\hline This paper & $\mathrm{X}$ & $\mathrm{X}$ & $\mathrm{X}$ & - & - & $\mathrm{X}$ & $\mathrm{X}$ & $\mathrm{X}$ & $\mathrm{X}$ & $\mathrm{X}$ & hard \\
\hline Bertels and Fahle (2006) & $\mathrm{X}$ & $\mathrm{X}$ & $\mathrm{X}$ & $\mathrm{X}$ & - & - & $\mathrm{x}$ & $\mathrm{X}$ & - & - & soft/hard \\
\hline Bredström and Rönnqvist (2008) & - & $\mathrm{X}$ & $\mathrm{X}$ & $\mathrm{X}$ & - & - & - & $\mathrm{X}$ & - & - & hard \\
\hline Di Gaspero and Urli (2014) & - & $\mathrm{x}$ & - & - & - & - & $\mathrm{x}$ & $\mathrm{X}$ & - & $\mathrm{X}$ & hard \\
\hline Dohn et al. (2008) & - & $\mathrm{X}$ & $\mathrm{X}$ & $\mathrm{X}$ & - & - & - & $\mathrm{X}$ & - & $\mathrm{X}$ & hard \\
\hline Hiermann et al. (2013) & $\mathrm{X}$ & $\mathrm{X}$ & $\mathrm{X}$ & - & - & - & - & $\mathrm{X}$ & - & $\mathrm{X}$ & hard \\
\hline Lanzarone and Matta (2014) & - & $\mathrm{X}$ & - & $\mathrm{X}$ & $\mathrm{X}$ & - & $\mathrm{X}$ & - & - & - & hard \\
\hline Mankowska et al. (2014) & - & $\mathrm{X}$ & - & - & $\mathrm{X}$ & - & - & $\mathrm{X}$ & - & - & hard \\
\hline Maya Duque et al. (2015) & $\mathrm{X}$ & $\mathrm{X}$ & - & $\mathrm{X}$ & - & - & - & - & $\mathrm{X}$ & - & hard \\
\hline Morito et al. (2013) & $\mathrm{X}$ & $\mathrm{X}$ & $\mathrm{X}$ & - & - & - & $\mathrm{x}$ & - & - & - & soft/hard \\
\hline Mutingi and Mbohwa (2014) & - & $\mathrm{X}$ & - & $\mathrm{X}$ & $\mathrm{X}$ & - & $\mathrm{X}$ & - & $\mathrm{X}$ & - & soft \\
\hline Rendl et al. (2012) & $\mathrm{X}$ & $\mathrm{X}$ & $\mathrm{X}$ & - & - & - & - & $\mathrm{X}$ & - & - & soft \\
\hline Trautsamwieser and Hirsch (2014) & $\mathrm{X}$ & $\mathrm{X}$ & $\mathrm{X}$ & - & - & - & - & & - & - & hard \\
\hline
\end{tabular}

Table 1: Overview of problem characteristics in recent academic literature

\subsection{Machine scheduling}

From a computational complexity point-of-view, the proposed decision support model shares similarities with (unrelated) parallel machine scheduling. In this context, flexible task durations are referred to as controllable processing times. Even in their most basic form, scheduling problems with controllable processing times are known to be NP-hard (Shabtay and Steiner, 2007).

HC scheduling problems in which tasks may be scheduled less often than a preferred frequency are similar to machine scheduling problems with job rejection. Furthermore, even in their most basic form, this type of scheduling problem is known to be NP-hard (Shabtay et al., 2013).

Scheduling problems with controllable processing times and job rejection have received some attention, mainly from a theoretical point-of-view, however, there is 
only one paper which addresses the combined problem integrating these two properties. Yang et al. (2014) proposed a metaheuristic for sequencing the jobs and, given this fixed job sequence, a polynomial-time algorithm determines each job's optimal start time, finishing time and compression time. Jobs whose finish times exceed the scheduling horizon are rejected.

\section{Problem definition}

\subsection{Home care problem}

Let $G=(V, A)$ be a complete directed graph with $V=\{1, \ldots,|V|\}$ the set of vertices and $A=\{(i, j): i, j \in V, i \neq j\}$ the set of arcs. The vertices in $G$ represent client homes and caregiver depots. Let $l_{i j}$ correspond to the distance between $i, j \in V$. The scheduling period $D=\{1, \ldots,|D|\}$ consists of $|D|$ consecutive days.

\subsubsection{Caregiver-related parameters}

Let $C=\{1, \ldots,|C|\}$ be the set of caregivers. Each individual caregiver $c \in C$ is characterized by a depot location $v_{c}$, either a central office or their home, which serves as the start and end location of the caregiver's daily route. Furthermore, each caregiver has a set of availabilities $A_{d}^{c}$ for each day $d \in D$, indicating the caregiver's working hours. These daily availabilities are modeled as a number of nonoverlapping hard time windows defined as intervals $\left[t w_{c d}^{-}, t w_{c d}^{+}\right)$. Let $\bar{m}_{c}$ represent the maximum number of clients a caregiver may visit per day. Current practice enforces $\bar{m}_{c}=2, \forall c \in C$, however, increasing this parameter intuitively enables greater efficiency of available staff. Finally, given that different caregivers may not always have guaranteed access to the same means of transportation, the travel time between locations $i, j \in V$ is caregiver- and day-dependent. More specifically, travel time $t_{i j}^{c d}$ is calculated as $a_{c d} \times l_{i j}$, where $a_{c d}$ constitutes a parameter representing the travel speed of caregiver $c$ on day $d$.

\subsubsection{Client-related parameters}

Let $K=\{1, \ldots,|K|\}$ be the set of clients. Each individual client $k \in K$ has a location $v_{k}$, typically their home, and a vector of preference costs $r_{k c}, \forall c \in C$ which are incurred when assigning a task associated with client $k$ to caregiver $c$. These costs are calculated based on several client and caregiver properties such as language proficiency, gender, smoking status and pet allergies. Finally, a set of tasks $T_{k}=\left\{1, \ldots\left|T_{k}\right|\right\}$ is associated with each client $k$. 


\subsubsection{Task-related parameters}

A task type is associated with both a client and an activity. A single client may be associated with multiple task types and, similarly, a single activity may be associated

with multiple task types. Each task type $t \in \bigcup_{k \in K} T_{k}$ must be scheduled once or more on days occurring in $D_{t} \subseteq D$. Note that a task type cannot be scheduled twice on the same day. Precisely how many times a task type must be scheduled in $D_{t}$ is determined by its frequency, defined as a minimum $f_{t}^{-}$and a preferred (upper bound) $f_{t}^{+}$such that $0 \leq f_{t}^{-} \leq f_{t}^{+}$. Note that the actual frequency could be zero or a value lower than the minimum. A task type may be scheduled fewer times than $f_{t}^{-}$, thereby incurring a proportional cost, but no more than $f_{t}^{+}$times. Each task's duration is bounded by a minimum (lower bound) $p_{t}^{-}$and a preferred (upper bound) $p_{t}^{+}$. Note that for duration, both the lower and upper bound are considered hard constraints, that is, a task should always last at least $p_{t}^{-}$time units and at most $p_{t}^{+}$ time units. A priority level, high or low, helps differentiate between the nature of different task types and reflects the undesirability of reducing the number of times a task type is scheduled. As with caregivers, there is a set of task availabilities $A_{d}^{t}$ for each day $d \in D$ indicating when a task $t \in T$ may be scheduled. Finally, a (sub)set of caregivers $C_{t} \subseteq C$ may be feasibly assigned to task type $t$ based on qualifications and hard preferences.

\subsubsection{Objective function}

The objective function constitutes a vital, yet highly complex element of the proposed model. The optimization objectives pertain not only to real KPIs as defined by the home care organizations' management, but also relaxed hard constraints which enforce a preferred structure on a solution. By way of handling the multitude of objectives, a lexicographic objective function is employed in which a multi-level hierarchy reflects the importance of each objective (Martinez-Legaz, 1988). The ordering in the lexicographic hierarchy was defined based on input provided by the home care organizations. The remainder of this section provides details concerning the different hierarchical levels of the model's objective function.

Levels 1 to 4 (MNH, MNL, PFH, PFL): The home care organizations identified the assignment of as many tasks as possible as the single most important objective. Consequently, the first four levels of the lexicographic ordering correspond to (i) deviation from minimum frequency for high priority tasks (MNH), (ii) deviation from minimum frequency for low priority tasks (MNL), (iii) deviation from preferred frequency for high priority tasks $(\mathrm{PFH})$ and (iv) deviation from preferred frequency for low priority tasks (PFL).

Level 5 (CVT): Caregivers and clients prefer a visit to last at least a given 
amount of time, to avoid both excessive switching between clients and also aid in the establishment of a relationship between client and caregiver. While this requirement may be considered a hard constraint, in practice, it is often impossible to satisfy and is therefore relaxed and incorporated as a soft constraint. Consequently, this hierarchical level attempts to minimize deviation from the minimum client visit time (CVT).

Level 6 (DUR): Similar to frequency, a task's duration may also be reduced, thereby facilitating more tasks to be scheduled. To prevent task durations from consistently reducing, this level minimizes the total deviation from the preferred task duration (DUR). If the deviation equals zero, the task is scheduled with its preferred duration.

Level 7 (TT): The total time spent by caregivers traveling between different clients represents a direct cost for home care organizations. Not only does it require financial compensation, but it also detracts from the time spent at client homes given that travel time is generally not explicitly scheduled. However, when caregivers are restricted to working within a single geographic region, travel time (TT) is typically relatively limited.

Level 8 (SPD): From a practical perspective, it is important to ensure task types are spread out whenever they are scheduled more than once during the scheduling period. The proposed model calculates the spreading cost (SPD) of each scheduled task as the absolute value of the difference between the ideal and actual spread. The ideal spread is calculated as the natural quotient of $\left|D_{t}\right|$ and the number of times a task is actually scheduled. The actual spread corresponds to the number of days between every pair of subsequently scheduled tasks. Note that a task may have been scheduled in the preceding scheduling period. The stepping horizon methodology proposed by Smet et al. (2017) is employed to correctly calculate this objective in such cases.

Level 9 (PRF): Clients typically have limited influence on the scheduling process. While not part of the formal contractual agreement with home care organizations, clients can often specify preferences for certain caregivers. However, since management's primary focus is on fulfilling the agreed-upon contracts, minimizing total preference cost (PRF) typically has a low priority.

\section{Solution approach}

Given the problem's inherently NP-hard status and limitations of state of the art integer programming solvers, a two-phase approach is proposed to generate effective solutions. A greedy heuristic first generates an initial solution, which is subsequently 
improved by a local search algorithm exploring various neighborhoods. Algorithm 1 outlines the proposed solution approach, with $f(\sigma)$ corresponding to the lexicographic evaluation function as defined in Section 3.1.4. A lexicographical comparison, denoted by $\preceq$, determines whether or not new solutions are accepted.

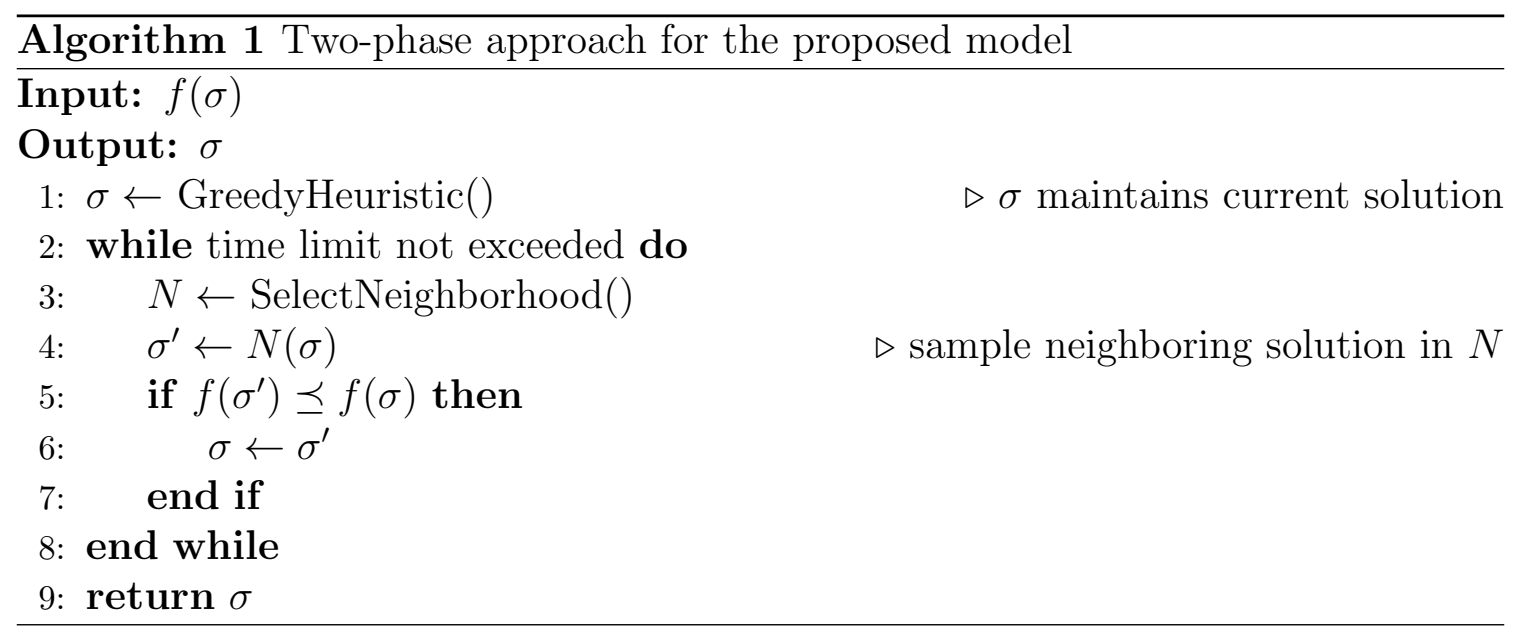

\subsection{Solution representation}

The proposed approach is based on an indirect solution representation. For each caregiver $c \in C$ and day $d \in D$, an ordered list of tuples is maintained representing the daily route of caregiver $c$ on day $d$. Each tuple is defined by a task $t$ and duration $p^{\prime}$, with $p_{t}^{-} \leq p^{\prime} \leq p_{t}^{+}$. The route $R_{c d}$ of caregiver $c$ on day $d$ is formally defined in Equation (1).

$$
R_{c d}=\left\langle\left(t_{1}, p_{1}^{\prime}\right),\left(t_{2}, p_{2}^{\prime}\right), \ldots,\left(t_{\left|R_{c d}\right|}, p_{\left|R_{c d}\right|}^{\prime}\right)\right\rangle
$$

Based on this representation, a schedule is constructed by taking each route as input for a serial schedule generation scheme (SSGS). The SSGS assigns tasks as early as possible, that is, it assigns the earliest possible start times while ensuring route feasibility (Kolisch, 1996). The order determined by the indirect solution representation is respected by the SSGS such that tuple $\left(t_{n}, p_{n}^{\prime}\right)$ will never be scheduled before $\left(t_{n-1}, p_{n-1}^{\prime}\right)$. Similar to the approach presented by Yang et al. (2014), each task whose earliest possible start time lies outside of the task's and caregiver's time windows is rejected. All objectives defined in Section 3.1.4 may be calculated directly based on the schedule generated by the SSGS. 


\subsection{Constructive heuristic}

The greedy algorithm constructs a solution by sorting tasks by earliest possible start time and employing priority as a tie-breaker. The heuristic subsequently assigns each task type $f_{t}^{+}$times to the best possible caregiver and day at the end of the route with its preferred duration $p_{t}^{+}$.

\subsection{Local search neighborhoods}

Each iteration of the local search improvement heuristic randomly selects one of nine neighborhoods. Rather than fully exploring the selected neighborhood, a single neighboring solution is sampled. The proposed neighborhood moves relate to (i) altering a task's assigned day, (ii) altering a task's assigned caregiver, (iii) changing the order of a route's tasks and (iv) modifying a task's duration. The following three intra-route neighborhoods are explored:

- Change order: given a route $R_{c d}$, swap two tuples in $R_{c d}$.

- Change duration: given tuple $\left(t_{i}, p_{i}^{\prime}\right)$ in a route $R_{c d}$, change $p_{i}^{\prime}$ to a value $p_{i}^{\prime \prime} \in$ $\left[p_{t}^{-}, p_{t}^{+}\right]: p_{i}^{\prime \prime} \neq p_{i}^{\prime}$.

- Group tasks: given route $R_{c d}$, group all tuples based on client location. This neighborhood seeks to directly minimize both CVT and TT.

In addition, the following six inter-route neighborhoods are explored:

- Change day: given two routes $R_{c d}$ and $R_{c d^{\prime}}$ with $d \neq d^{\prime}$, move a randomly selected tuple $\left(t_{i}, p_{i}^{\prime}\right)$ from $R_{c d}$ to a random position in $R_{c d^{\prime}}$.

- Change caregiver: given two routes $R_{c d}$ and $R_{c^{\prime} d}$ with $c \neq c^{\prime}$, move a randomly selected tuple $\left(t_{i}, p_{i}^{\prime}\right)$ from $R_{c d}$ to a random position in $R_{c^{\prime} d}$.

- Change day and caregiver: given two routes $R_{c d}$ and $R_{c^{\prime} d^{\prime}}$ with $c \neq c^{\prime}$ and $d \neq d^{\prime}$, move a randomly selected tuple $\left(t_{i}, p_{i}^{\prime}\right)$ from $R_{c d}$ to a random position in $R_{c^{\prime} d^{\prime}}$.

- Swap caregivers: given two routes $R_{c d}$ and $R_{c^{\prime} d}$ with $c \neq c^{\prime}$, swap a tuple $\left(t_{i}, p_{i}^{\prime}\right)$ randomly selected from $R_{c d}$ with a tuple $\left(t_{j}, p_{j}^{\prime}\right)$ randomly selected from $R_{c^{\prime} d}$ such that $t_{i} \neq t_{j}$.

- Move chain: given two routes $R_{c d}$ and $R_{c^{\prime} d}$ with $c \neq c^{\prime}$, a chain of tuples is moved to a random position in $R_{c^{\prime} d}$. This chain is constructed by first randomly selecting one tuple $\left(t_{i}, p_{i}^{\prime}\right)$ and then obtaining the sequence of tuples $\left(t_{j}, p_{j}^{\prime}\right), \ldots,\left(t_{i}, p_{i}^{\prime}\right), \ldots,\left(t_{k}, p_{k}^{\prime}\right)$ within $R_{c d}$ and which share the same client. 
- Move chain day: given two routes $R_{c d}$ and $R_{c^{\prime} d^{\prime}}$ with $c \neq c^{\prime}$ and $d \neq d^{\prime}$, move a chain of tuples $\left(t_{i}, p_{i}^{\prime}\right), \ldots,\left(t_{j}, p_{j}^{\prime}\right)$ appearing consecutively within $R_{c d}$ and which share the same client, from $R_{c d}$ to a random position in $R_{c^{\prime} d^{\prime}}$. This chain is constructed as defined in the move chain neighborhood.

- Swap chain: given two routes $R_{c d}$ and $R_{c^{\prime} d}$ with $c \neq c^{\prime}$, swap a chain of tuples $\left(t_{i}, p_{i}^{\prime}\right), \ldots,\left(t_{j}, p_{j}^{\prime}\right)$ appearing consecutively within $R_{c d}$ and which share the same client with a chain of tuples $\left(t_{k}, p_{k}^{\prime}\right), \ldots,\left(t_{h}, p_{h}^{\prime}\right)$ appearing consecutively within $R_{c^{\prime} d}$ and which share the same client. This chain is constructed as defined in the move chain neighborhood.

Given that the proposed neighborhood operators only modify up to two routes, delta evaluation only assesses the changed routes of a neighboring solution, thereby significantly reducing computation time when compared against completely re-evaluating each new solution. Furthermore, note that all neighborhoods maintain feasibility in the current solution.

\section{Computational experiments}

A series of computational experiments was conducted to quantify the individual impact of three types of scheduling flexibility in the proposed model: (i) scheduling with disaggregated tasks vs scheduling with aggregated tasks, (ii) task duration flexibility vs fixed task duration, and (iii) increasing the maximum number of clients a caregiver may visit per day. The results are analyzed in order to derive a general methodology for improving service quality in home care.

\subsection{Data and experimental setup}

Data was obtained directly from Flemish home care organizations, describing, for two geographic regions, the available caregivers and the task types associated with each client. The considered scheduling period is one week and the minimum client visit time is 45 minutes. Table 2 provides an overview of the 20 problem instances composing the dataset. These instances are publicly-accessible online ${ }^{1}$. The primary difference between the two regions is that Region 1 suffers from severe understaffing, that is, there are not enough caregivers in Region 1 to fulfill the clients' preferred task demand. Primarily a consequence of how, despite there being fewer caregivers

\footnotetext{
${ }^{1}$ https://people.cs.kuleuven.be/ federico.mosquera/homecare.html
} 


\begin{tabular}{|c|c|c|c|c|c|c|c|c|c|c|c|c|c|c|c|c|c|c|c|c|}
\hline & & \multirow[b]{3}{*}{$\begin{array}{l}\text { Number } \\
\text { of clients }\end{array}$} & \multirow[b]{3}{*}{$\begin{array}{l}\text { Number of } \\
\text { caregivers }\end{array}$} & \multirow[b]{3}{*}{$\begin{array}{c}\text { Caregiver } \\
\text { availability }\end{array}$} & \multirow{2}{*}{\multicolumn{2}{|c|}{ Total tasks duration }} & \multicolumn{7}{|c|}{ Disaggregated } & \multicolumn{7}{|c|}{ Aggregated } \\
\hline & & & & & & & & & Minimum & & & Preferred & & & & Mіпітит & & & Preferred & \\
\hline \multicolumn{2}{|c|}{ Instance } & & & & Minimum & Preferred & $\begin{array}{l}\text { Number of } \\
\text { task types }\end{array}$ & $\begin{array}{l}\text { Number } \\
\text { of tasks }\end{array}$ & $\begin{array}{l}\text { Average task } \\
\text { frequency }\left({ }^{*}\right)\end{array}$ & $\begin{array}{l}\text { Average } \\
\text { duration }\end{array}$ & $\begin{array}{l}\text { Number } \\
\text { of tasks }\end{array}$ & $\begin{array}{l}\text { Average task } \\
\text { frequency }\left({ }^{*}\right)\end{array}$ & $\begin{array}{l}\text { Average } \\
\text { duration }\end{array}$ & $\begin{array}{l}\text { Number of } \\
\text { task types }\end{array}$ & $\begin{array}{l}\text { Number } \\
\text { of tasks }\end{array}$ & $\begin{array}{l}\text { Average task } \\
\text { frequency }\left({ }^{*}\right)\end{array}$ & $\begin{array}{l}\text { Average } \\
\text { duration }\end{array}$ & $\begin{array}{l}\text { Number } \\
\text { of tasks }\end{array}$ & $\begin{array}{l}\text { Average task } \\
\text { frequency }\left({ }^{*}\right)\end{array}$ & $\begin{array}{l}\text { Average } \\
\text { duration }\end{array}$ \\
\hline Region 1 & Week 1 & 98 & 25 & $559 \mathrm{~h} 45 \mathrm{~m}$ & $375 \mathrm{~h} 50 \mathrm{~m}$ & $823 \mathrm{~h} 45 \mathrm{~m}$ & 893 & 1157 & 1.30 & oh $19 \mathrm{~m}$ & 1428 & 1.60 & oh $34 \mathrm{~m}$ & 98 & 191 & 1.95 & 1h $56 \mathrm{~m}$ & 233 & 2.38 & $3 \mathrm{~h} 30 \mathrm{~m}$ \\
\hline Region 1 & Week 2 & 98 & 26 & $594 \mathrm{~h} 15 \mathrm{~m}$ & $376 \mathrm{~h} 20 \mathrm{~m}$ & $824 \mathrm{~h} 30 \mathrm{~m}$ & 894 & 1158 & 1.30 & $0 \mathrm{~h} 19 \mathrm{~m}$ & 1429 & 1.60 & $0 \mathrm{~h} 34 \mathrm{~m}$ & 98 & 191 & 1.95 & $1 \mathrm{~h} 56 \mathrm{~m}$ & 233 & 2.38 & $3 \mathrm{~h} 31 \mathrm{~m}$ \\
\hline Region 1 & Week 3 & 98 & 26 & $524 \mathrm{~h} 30 \mathrm{~m}$ & $376 \mathrm{~h} 20 \mathrm{~m}$ & $824 \mathrm{~h} 30 \mathrm{~m}$ & 894 & 1158 & 1.30 & oh 19m & 1429 & 1.60 & $0 \mathrm{~h} 34 \mathrm{~m}$ & 98 & 191 & 1.95 & $1 \mathrm{~h} 56 \mathrm{~m}$ & 233 & 2.38 & $3 \mathrm{~h} 31 \mathrm{~m}$ \\
\hline Region 1 & Week 4 & 98 & 27 & $602 \mathrm{~h} 30 \mathrm{~m}$ & $376 \mathrm{~h} 20 \mathrm{~m}$ & $824 \mathrm{~h} 30 \mathrm{~m}$ & 894 & 1158 & 1.30 & Oh $19 \mathrm{~m}$ & 1429 & 1.60 & $0 \mathrm{~h} 34 \mathrm{~m}$ & 98 & 191 & 1.95 & $1 \mathrm{~h} 56 \mathrm{~m}$ & 233 & 2.38 & $3 \mathrm{~h} 31 \mathrm{~m}$ \\
\hline Region 1 & Week 5 & 99 & 26 & $562 \mathrm{~h} 00 \mathrm{~m}$ & $378 \mathrm{~h} 20 \mathrm{~m}$ & $830 \mathrm{~h} 00 \mathrm{~m}$ & 900 & 1164 & 1.29 & oh $19 \mathrm{~m}$ & 1435 & 1.59 & $0 \mathrm{~h} 34 \mathrm{~m}$ & 99 & 192 & 1.94 & $1 \mathrm{~h} 56 \mathrm{~m}$ & 235 & 2.37 & $3 \mathrm{~h} 30 \mathrm{~m}$ \\
\hline Region 1 & Week 6 & 99 & 26 & 491h 00m & $378 \mathrm{~h} 20 \mathrm{~m}$ & $830 \mathrm{~h} 00 \mathrm{~m}$ & 900 & 1164 & 1.29 & $0 \mathrm{~h} 19 \mathrm{~m}$ & 1435 & 1.59 & $0 \mathrm{~h} 34 \mathrm{~m}$ & 99 & 192 & 1.94 & 1h $56 \mathrm{~m}$ & 235 & 2.37 & $3 \mathrm{~h} 30 \mathrm{~m}$ \\
\hline Region 1 & Week 7 & 99 & 27 & $544 \mathrm{~h} 00 \mathrm{~m}$ & $378 \mathrm{~h} 20 \mathrm{~m}$ & $830 \mathrm{~h} 00 \mathrm{~m}$ & 900 & 1164 & 1.29 & $0 \mathrm{~h} \mathrm{19m}$ & 1435 & 1.59 & $0 \mathrm{~h} 34 \mathrm{~m}$ & 99 & 192 & 1.94 & 1h $56 \mathrm{~m}$ & 235 & 2.37 & $3 \mathrm{~h} 30 \mathrm{~m}$ \\
\hline Region 1 & Week 8 & 99 & 26 & $536 \mathrm{~h} 45 \mathrm{~m}$ & $378 \mathrm{~h} 20 \mathrm{~m}$ & $830 \mathrm{~h} 00 \mathrm{~m}$ & 900 & 1164 & 1.29 & 0h $19 \mathrm{~m}$ & 1435 & 1.59 & $0 \mathrm{~h} 34 \mathrm{~m}$ & 99 & 192 & 1.94 & $1 \mathrm{~h} 56 \mathrm{~m}$ & 235 & 2.37 & $3 \mathrm{~h} 30 \mathrm{~m}$ \\
\hline Region 1 & Week 9 & 99 & 25 & $529 \mathrm{~h} 00 \mathrm{~m}$ & $378 \mathrm{~h} 20 \mathrm{~m}$ & $830 \mathrm{~h} 00 \mathrm{~m}$ & 900 & 1164 & 1.29 & $0 \mathrm{~h} 19 \mathrm{~m}$ & 1435 & 1.59 & $0 \mathrm{~h} 34 \mathrm{~m}$ & 99 & 192 & 1.94 & $1 \mathrm{~h} 56 \mathrm{~m}$ & 235 & 2.37 & $3 \mathrm{~h} 30 \mathrm{~m}$ \\
\hline Region 1 & Week 10 & 94 & 28 & $711 \mathrm{~h} 00 \mathrm{~m}$ & $385 \mathrm{~h} 05 \mathrm{~m}$ & $839 \mathrm{~h} 30 \mathrm{~m}$ & 870 & 1123 & 1.29 & $0 \mathrm{~h} 20 \mathrm{~m}$ & 1375 & 1.58 & $0 \mathrm{~h} 36 \mathrm{~m}$ & 94 & 189 & 2.01 & $2 \mathrm{~h} \mathrm{00m}$ & 233 & 2.48 & $3 \mathrm{~h} 34 \mathrm{~m}$ \\
\hline Region 2 & Week 1 & 113 & 23 & $618 \mathrm{~h} \mathrm{00m}$ & $451 \mathrm{~h} 25 \mathrm{~m}$ & $607 \mathrm{~h} 50 \mathrm{~m}$ & 492 & 599 & 1.22 & 0h $45 \mathrm{~m}$ & 701 & 1.42 & 0h $52 \mathrm{~m}$ & 113 & 206 & 1.82 & $2 \mathrm{~h} \mathrm{11m}$ & 220 & 1.95 & $2 \mathrm{~h} 45 \mathrm{~m}$ \\
\hline Region 2 & Week 2 & 115 & 25 & $529 \mathrm{~h} \mathrm{00m}$ & $457 \mathrm{~h} 40 \mathrm{~m}$ & $619 \mathrm{~h} 50 \mathrm{~m}$ & 50 & 60 & 1.21 & $0 \mathrm{~h} 45 \mathrm{~m}$ & 71 & 1.42 & Oh 52 & 115 & 209 & 1.82 & $2 \mathrm{~h} 11 \mathrm{~m}$ & 223 & 1.94 & $2 \mathrm{~h} 46 \mathrm{~m}$ \\
\hline Region 2 & Week 3 & 115 & 25 & $623 \mathrm{~h} 10 \mathrm{~m}$ & $457 \mathrm{~h} 40 \mathrm{~m}$ & $619 \mathrm{~h} 50 \mathrm{~m}$ & 501 & 608 & 1.21 & 0h $45 \mathrm{~m}$ & 713 & 1.42 & Oh 52 & 115 & 209 & 1.82 & $2 \mathrm{~h} 11 \mathrm{~m}$ & 223 & 1.94 & $2 \mathrm{~h} 46 \mathrm{~m}$ \\
\hline Region 2 & Week 4 & 123 & 22 & $529 \mathrm{~h} \mathrm{00m}$ & $482 \mathrm{~h} 45 \mathrm{~m}$ & $653 \mathrm{~h} 45 \mathrm{~m}$ & 524 & 631 & 1.20 & $0 \mathrm{~h} 45 \mathrm{~m}$ & 742 & 1.42 & $0 \mathrm{~h} 52 \mathrm{~m}$ & 123 & 221 & 1.80 & $2 \mathrm{~h} 10 \mathrm{~m}$ & 235 & 1.91 & $2 \mathrm{~h} 46 \mathrm{~m}$ \\
\hline Region 2 & Week 5 & 125 & 23 & $587 \mathrm{~h} 46 \mathrm{~m}$ & $488 \mathrm{~h} 40 \mathrm{~m}$ & $663 \mathrm{~h} 50 \mathrm{~m}$ & 532 & 639 & 1.20 & 0h $45 \mathrm{~m}$ & 754 & 1.42 & $0 \mathrm{~h} 52 \mathrm{~m}$ & 125 & 224 & 1.79 & $2 \mathrm{~h} 10 \mathrm{~m}$ & 238 & 1.90 & $2 \mathrm{~h} 47 \mathrm{~m}$ \\
\hline Region 2 & Week 6 & 125 & 19 & 291h 00m & $488 \mathrm{~h} 40 \mathrm{~m}$ & $663 \mathrm{~h} 50 \mathrm{~m}$ & 532 & 639 & 1.20 & $0 \mathrm{~h} 45 \mathrm{~m}$ & 754 & 1.42 & $0 \mathrm{~h} 52 \mathrm{~m}$ & 125 & 224 & 1.79 & $2 \mathrm{~h} 10 \mathrm{~m}$ & 238 & 1.90 & $2 \mathrm{~h} 47 \mathrm{~m}$ \\
\hline Region 2 & Week 7 & 125 & 22 & $442 \mathrm{~h} 45 \mathrm{~m}$ & $488 \mathrm{~h} 40 \mathrm{~m}$ & $663 \mathrm{~h} 50 \mathrm{~m}$ & 532 & 639 & 1.20 & oh $45 \mathrm{~m}$ & 754 & 1.42 & oh $52 \mathrm{~m}$ & 125 & 224 & 1.79 & $2 \mathrm{~h} 10 \mathrm{~m}$ & 238 & 1.90 & $2 \mathrm{~h} 47 \mathrm{~m}$ \\
\hline Region 2 & Week 8 & 125 & 22 & $530 \mathrm{~h} 30 \mathrm{~m}$ & $488 \mathrm{~h} 40 \mathrm{~m}$ & $663 \mathrm{~h} 50 \mathrm{~m}$ & 532 & 639 & 1.20 & $0 \mathrm{~h} 45 \mathrm{~m}$ & 754 & 1.42 & $0 \mathrm{~h} 52 \mathrm{~m}$ & 125 & 224 & 1.79 & $2 \mathrm{~h} \mathrm{10 \textrm {m }}$ & 238 & 1.90 & $2 \mathrm{~h} 47 \mathrm{~m}$ \\
\hline Region 2 & Week 9 & 127 & 22 & $509 \mathrm{~h} 45 \mathrm{~m}$ & $492 \mathrm{~h} 40 \mathrm{~m}$ & $671 \mathrm{~h} 50 \mathrm{~m}$ & 538 & 645 & 1.20 & $0 \mathrm{~h} 45 \mathrm{~m}$ & 760 & 1.41 & $0 \mathrm{~h} 53 \mathrm{~m}$ & 127 & 226 & 1.78 & $2 \mathrm{~h} \mathrm{10m}$ & 240 & $\begin{array}{l}1.89 \\
1.89\end{array}$ & $2 \mathrm{~h} 47 \mathrm{~m}$ \\
\hline Region 2 & Week 10 & 127 & 21 & $479 \mathrm{~h} 00 \mathrm{~m}$ & $492 \mathrm{~h} 40 \mathrm{~m}$ & $671 \mathrm{~h} 50 \mathrm{~m}$ & 538 & 645 & 1.20 & $0 \mathrm{~h} 45 \mathrm{~m}$ & 760 & 1.41 & oh $53 \mathrm{~m}$ & 127 & 226 & 1.78 & $2 \mathrm{~h} 10 \mathrm{~m}$ & 240 & 1.89 & 2h $47 \mathrm{~m}$ \\
\hline
\end{tabular}

Table 2: Instance characteristics. Number of task types references, for all clients, the possible individual tasks (such as cooking and cleaning) in a dissagregated context or a single block of tasks in an aggregated context. Number of tasks refers to the minimum/preferred number of tasks during the scheduling period. Given some tasks must be conducted more than once during the reference period, both numbers are higher than Number of task types. Number of task types and Number of tasks are illustrated in Example 5.1. Average task frequency $\left({ }^{*}\right)$ refers to the ratio between these two values, which is calculated by dividing Number of tasks by the number of Number of task types. 
and more clients, those clients are less care-intensive. The variation between weeks within each region is limited and typically caused by short-term absences or task cancellations due to client hospitalization. Figures 2 and 3 illustrate the geographic distribution of required care in both regions. Each point maps the geographic location of a client, with its size indicating the number of weekly hours of care required. Clearly, Region 1 is associated with more sparsely-located clients, while Region 2 has more clustered clients in a smaller geographic area. These regional differences impact the total travel time and have an even more profound impact when the number of clients a caregiver may visit each day is increased.

Example 5.1. The difference between task type and task, which is shown in Table 2, is illustrated with the following example. Consider Ruben and Maria as clients of the home care organization who both require help with household activities. Both Ruben and Maria require assistance cleaning their houses once or twice per week, which corresponds to minimum and preferred frequency respectively. Furthermore, Maria additionally requires help cooking two to four times per week. A task type is associated with both a client and an activity. A single client may be associated with multiple task types and, similarly, a single activity may be associated with multiple task types. For instance, in the aforementioned example the number of task types is three, that is, a cleaning task type for Ruben and both a cleaning and a cooking task type for Maria. By contrast, the number of tasks counts either the minimum or preferred frequency for all task types, which are those tasks which may be assigned during a scheduling period. Referring again to the aforementioned example, the number of tasks equals four (cleaning for Ruben, cleaning for Maria, cooking twice for Maria) when respecting the minimum frequency. The number of tasks increased to eight when Ruben and Marias preferred frequencies are considered.

The problem instances provided by the home care organizations were specified to the level of disaggregated tasks rather than aggregated tasks, in accordance with their current practice. Therefore, the proposed experiments require instances which represent the clients' care as one aggregated block in order to simulate scheduling with aggregated tasks. To this end, a methodology derived from current practice in the aforementioned home care organizations was employed which transforms the provided disaggregated instances into instances in which clients have a single task whose duration equals the total number of hours of required care. For each client, first, the total amount of required care is calculated by summing all disaggregated tasks. This total duration is subsequently divided into large blocks of care which are restricted in length. For example, if a client's total amount of required care is 12 hours, this demand is transformed into one task with a duration of four hours, and a frequency of three. Note that this procedure occurs for both the minimum and preferred levels of care.

A time limit of 30 minutes was imposed for each experiment, reflecting acceptable real-world conditions. Each experiment was run ten times, with the reported values representing the average of these ten runs. All experiments were conducted on a Dell Poweredge T620, 2x Intel Xeon E5-2670, 128GB RAM. 

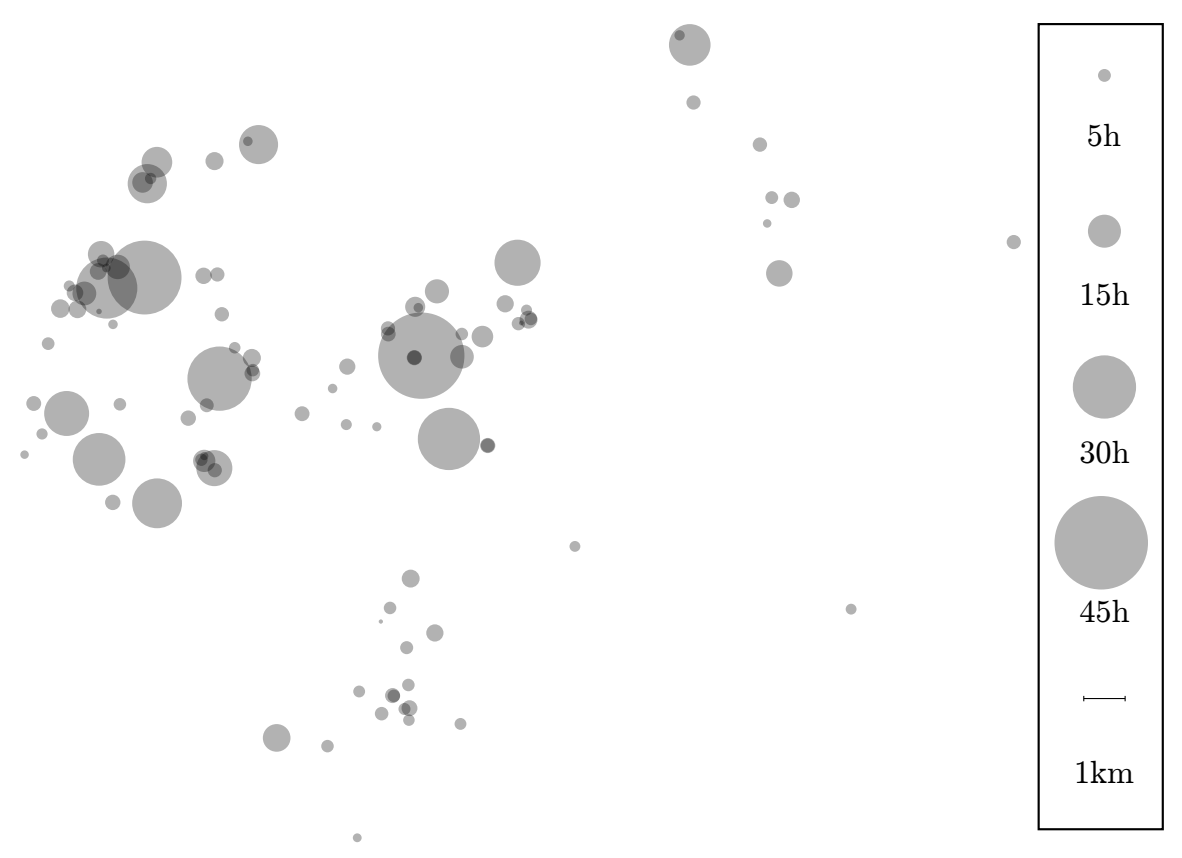

Figure 2: The geographic distribution of weekly required hours of care throughout Region 1.

\subsection{Algorithm performance}

The heuristic's performance was evaluated via a series of experiments conducted using an integer linear programming (ILP) formulation of the problem. The goal was to compare the primary objectives, namely levels $1-4$, which constitute the home care organization's main profit drivers. The ILP formulation, presented in Appendix A, was solved with CPLEX 12.7 configured to use two threads with a time limit of 24 hours.

Tables 3 and 4 detail, for the aggregated and disaggregated instances respectively, the local search objective value (Value). Min in both tables denotes a lower bound on the objective value computed using the integer programming formulation from Appendix A. For example, when considering Level 1 (MNH), the MIP lower bound in Table 4 for Region 1 - Flexible task duration is 0 , implying that all tasks of minimum frequency and high priority can be assigned. The lower bound value obtained may be a very weak given that the MIP was often unable to generate any feasible solution. To compute lower bounds for the subsequent lexicographic objectives, the best feasible solution (here obtained by local search) constrains the values of all preceding objectives. For example, Level 2 (MNL) is constrained by the best value obtained by local search for MNH. The lower bounds for the remaining objectives are computed in a similar fashion. 


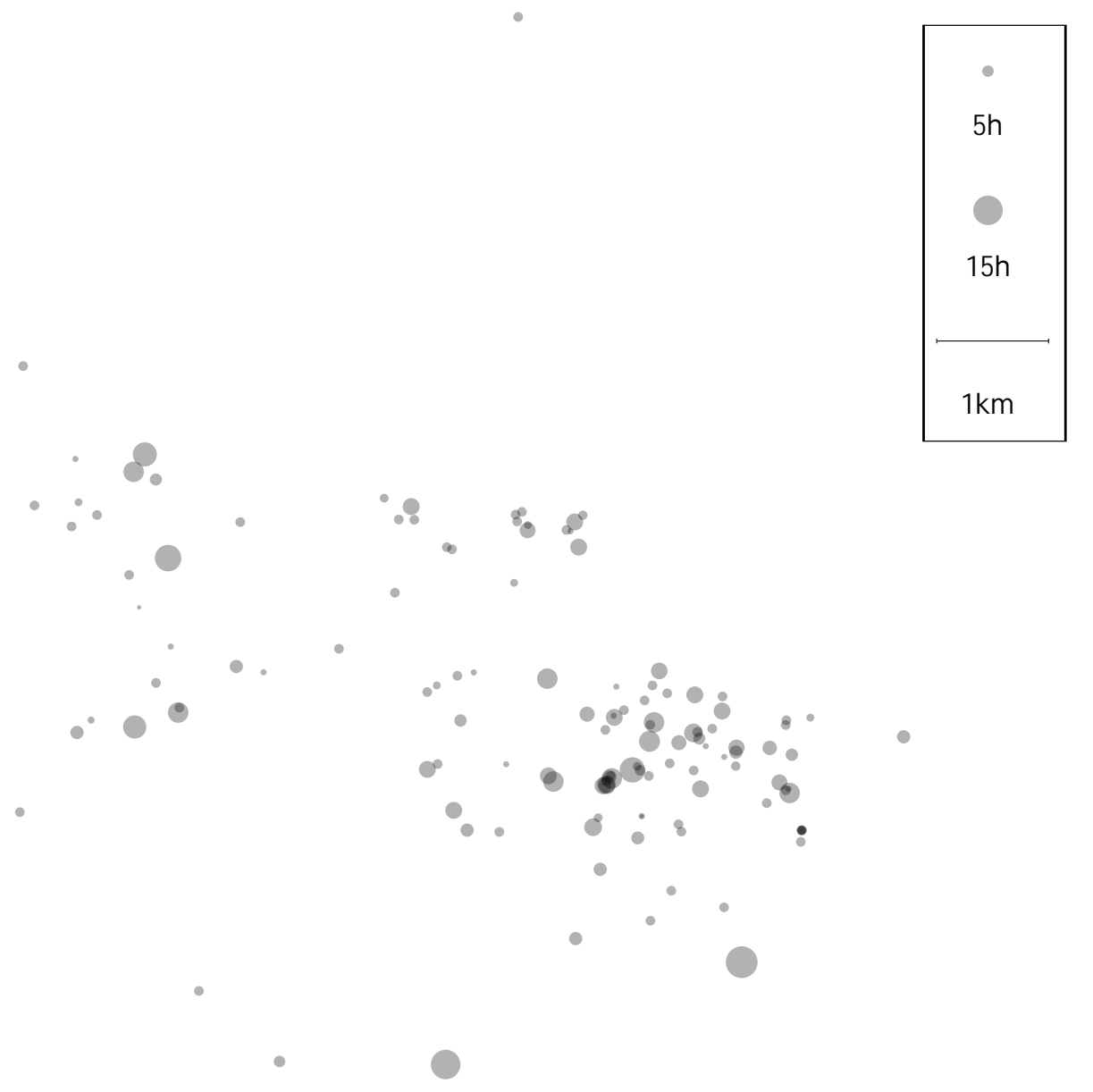

Figure 3: The geographic distribution of weekly required hours of care throughout Region 2.

Max refers to the worst value this levels objective could possibly take, calculated by simply counting the maximum number of tasks which may remain unassigned. For example, in Table 4 for Region 1 - Flexible task duration, the value of Level 1 $(\mathrm{MNH})$ is 866.1. This value corresponds to a situation in which all high priority tasks remain unassigned. The max value of all subsequent objectives is determined similarly. Distance (Dist. (\%)) is used as a relative quality metric and is calculated as:

$$
\text { Dist. }(\%)=\frac{(\text { Value }- \text { Min })}{(\text { Max }- \text { Min })} * 100
$$

The reported values are averages over all weeks, grouped by the maximum num- 
ber of clients a caregiver may visit per day $\left(\bar{m}_{c}\right)$ and by task duration flexibility. It is noteworthy to mention that the proposed heuristic performs better for the disaggregated instances which require significantly more tasks to be scheduled.

Note that CPLEX was not able to compute the minimum attainable values for the disaggregated instances, despite computing for 24 hours and using high amounts of memory. The best minimum bounds remain therefore zero for these instances.

\begin{tabular}{|c|c|c|c|c|c|c|c|c|c|c|c|c|c|c|c|c|}
\hline & \multicolumn{16}{|c|}{ Objectives } \\
\hline & \multicolumn{4}{|c|}{ Level $1(M N H)$} & \multicolumn{4}{|c|}{ Level 2 (MNL) } & \multicolumn{4}{|c|}{ Level 3 (PFH) } & \multicolumn{4}{|c|}{ Level 4 (PFL) } \\
\hline & Value & Dist.(\%) & Min & $\operatorname{Max}$ & Value & Dist.(\%) & Min & $\operatorname{Max}$ & Value & Dist.(\%) & Min & Max & Value & Dist.(\%) & Min & Max \\
\hline \multicolumn{17}{|c|}{ Region 1 - Flexible task duration } \\
\hline $\bar{m}_{c}=2$ & 12.2 & 5.6 & 1.8 & 188.3 & 0.1 & 3.7 & 0.0 & 3.0 & 51.0 & 21.5 & 1.8 & 231.0 & 0.1 & 3.7 & 0.0 & 3.0 \\
\hline $\begin{array}{l}\bar{m}_{c}=3 \\
m_{c}\end{array}$ & 2.7 & 0.5 & 1.8 & 188.3 & 0.0 & 0.0 & 0.0 & 3.0 & 21.7 & 8.7 & 1.8 & 231.0 & 0.0 & 0.0 & 0.0 & 3.0 \\
\hline $\bar{m}_{c}=4$ & 2.5 & 0.4 & 1.8 & 188.3 & 0.0 & 0.0 & 0.0 & 3.0 & 19.1 & 7.5 & 1.8 & 231.0 & 0.0 & 0.0 & 0.0 & 3.0 \\
\hline $\bar{m}_{c}=5$ & 2.6 & 0.4 & 1.8 & 188.3 & 0.0 & 0.0 & 0.0 & 3.0 & 18.9 & 7.5 & 1.8 & 231.0 & 0.0 & 0.0 & 0.0 & 3.0 \\
\hline $\bar{m}_{c}=6$ & 2.5 & 0.4 & 1.8 & 188.3 & 0.0 & 0.0 & 0.0 & 3.0 & 18.8 & 7.4 & 1.8 & 231.0 & 0.0 & 0.0 & 0.0 & 3.0 \\
\hline Average & 4.5 & 1.5 & 1.8 & 188.3 & 0.0 & 0.7 & 0.0 & 3.0 & 25.9 & 10.5 & 1.8 & 231.0 & 0.0 & 0.7 & 0.0 & 3.0 \\
\hline \multicolumn{17}{|c|}{ Region 1 - Fixed task duration } \\
\hline $\bar{m}_{c}=2$ & 45.1 & 17.4 & 15.1 & 188.3 & 0.4 & 14.7 & 0.0 & 3.0 & 87.4 & 31.6 & 21.3 & 231.0 & 0.4 & 14.7 & 0.0 & 3.0 \\
\hline $\bar{m}_{c}=3$ & 40.6 & 14.8 & 15.1 & 188.3 & 0.1 & 3.0 & 0.0 & 3.0 & 80.6 & 28.3 & 21.3 & 231.0 & 0.1 & 3.0 & 0.0 & 3.0 \\
\hline $\bar{m}_{c}=4$ & 40.3 & 14.6 & 15.1 & 188.3 & 0.1 & 4.0 & 0.0 & 3.0 & 80.4 & 28.3 & 21.3 & 231.0 & 0.1 & 4.0 & 0.0 & 3.0 \\
\hline $\bar{m}_{c}=5$ & 40.3 & 14.6 & 15.1 & 188.3 & 0.1 & 2.3 & 0.0 & 3.0 & 80.3 & 28.2 & 21.3 & 231.0 & 0.1 & 2.3 & 0.0 & 3.0 \\
\hline $\begin{array}{l}\bar{m}_{c}=6 \\
=x^{2}\end{array}$ & 40.3 & 14.6 & 15.1 & 188.3 & 0.1 & 3.3 & 0.0 & 3.0 & 80.4 & 28.2 & 21.3 & 231.0 & 0.1 & 3.3 & 0.0 & 3.0 \\
\hline Average & 41.3 & 15.2 & 15.1 & 188.3 & 0.2 & 5.5 & 0.0 & 3.0 & 81.8 & 28.9 & 21.3 & 231.0 & 0.2 & 5.5 & 0.0 & 3.0 \\
\hline \multicolumn{17}{|c|}{ Region 2 - Flexible task duration } \\
\hline $\bar{m}_{c}=2$ & 8.1 & 5.2 & 0.0 & 153.6 & 46.6 & 69.4 & 0.0 & 65.7 & 22.1 & 12.6 & 1.0 & 167.6 & 46.6 & 69.4 & 0.0 & 65.7 \\
\hline $\bar{m}_{c}=3$ & 5.1 & 3.3 & 0.0 & 153.6 & 23.6 & 34.8 & 0.0 & 65.7 & & 9.3 & 1.0 & 167 & 23.6 & 34.8 & 0.0 & 65.7 \\
\hline $\begin{array}{l}m_{c}- \\
\bar{m}_{c}=4\end{array}$ & 4.7 & 3.0 & 0.0 & 153.6 & 20.3 & 30.0 & 0.0 & 65.7 & 16.0 & 9.0 & 1.0 & 167.6 & 20.3 & 30.0 & 0.0 & 65.7 \\
\hline $\bar{m}_{c}=5$ & 4.6 & 3.0 & 0.0 & 153.6 & 20.3 & 30.0 & 0.0 & 65.7 & 15.9 & 8.9 & 1.0 & 167.6 & 20.3 & 30.0 & 0.0 & 65.7 \\
\hline $\bar{m}_{c}=6$ & 4.4 & 2.9 & 0.0 & 153.6 & 20.3 & 30.0 & 0.0 & 65.7 & 15.9 & 8.9 & 1.0 & 167.6 & 20.3 & 30.0 & 0.0 & 65.7 \\
\hline Average & 5.4 & 3.5 & 0.0 & 153.6 & 26.2 & 38.8 & 0.0 & 65.7 & 17.3 & 9.7 & 1.0 & 167.6 & 26.2 & 38.8 & 0.0 & $\begin{array}{llll}65.7 & & & \\
\end{array}$ \\
\hline \multicolumn{17}{|c|}{ Region 2 - Fixed task duration } \\
\hline $\bar{m}_{c}=2$ & 15.4 & 9.5 & 0.7 & 153.6 & 46.5 & 69.3 & 0.0 & 65.7 & 29.4 & 16.6 & 1.7 & 167.6 & 46.5 & 69.3 & 0.0 & 65.7 \\
\hline $\bar{m}_{c}=3$ & 13.5 & 8.3 & 0.7 & 153.6 & 31.9 & 47.2 & 0.0 & 65.7 & 25.8 & 14.4 & 1.7 & 167.6 & 31.9 & 47.2 & 0.0 & 65.7 \\
\hline $\begin{array}{l}\bar{m}_{c}=4 \\
\end{array}$ & 13.0 & 8.0 & 0.7 & 153.6 & $\begin{array}{l}32.7 \\
32\end{array}$ & 48.3 & 0.0 & 65.7 & 25.2 & 14.1 & 1.7 & 167.6 & 32.7 & $\begin{array}{l}1.2 . \\
48.3\end{array}$ & 0.0 & 65.7 \\
\hline $\bar{m}_{c}=5$ & 13.0 & 8.0 & 0.7 & 153.6 & 32.8 & 48.6 & 0.0 & 65.7 & 25.1 & 14.0 & 1.7 & 167.6 & 32.8 & 48.6 & 0.0 & 65.7 \\
\hline $\bar{m}_{c}=6$ & 13.0 & 8.0 & 0.7 & 153.6 & 32.8 & 48.4 & 0.0 & 65.7 & 25.1 & 14.0 & 1.7 & 167.6 & 32.8 & 48.4 & 0.0 & 65.7 \\
\hline Average & 13.6 & 8.4 & 0.7 & 153.6 & 35.3 & 52.4 & 0.0 & 65.7 & 26.1 & 14.6 & 1.7 & 167.6 & 35.3 & 52.4 & 0.0 & 65.7 \\
\hline
\end{tabular}

Table 3: Computational results for aggregated instances. MNH/MNL: deviation from minimum frequency for high/low priority tasks, PFH/PFL: deviation from preferred frequency for high/low priority tasks.

\subsection{Impact of scheduling with disaggregated tasks}

This section quantifies the individual effect of scheduling with disaggregated tasks compared against aggregated tasks while maintaining fixed task duration and a maximum of two clients each caregiver may visit per day $\left(\bar{m}_{c}=2\right)$. Intuitively, the benefits of disaggregation are self-evident: it enables a more fine-grained definition of the required care per client and allows different priority levels to be associated with the task types, thereby clearly defining which task types are more important than others.

Table 5 details, for both aggregated and disaggregated instances, the deviation from the minimum client visit time (CVT), total travel time (TT), spreading costs 


\begin{tabular}{|c|c|c|c|c|c|c|c|c|c|c|c|c|c|c|c|c|}
\hline & \multicolumn{16}{|c|}{ Objectives } \\
\hline & \multicolumn{4}{|c|}{ Level $1(M N H)$} & \multicolumn{4}{|c|}{ Level $2(M N L)$} & \multicolumn{4}{|c|}{ Level $3(\mathrm{PFH})$} & \multicolumn{4}{|c|}{ Level 4 (PFL) } \\
\hline & Value & Dist.(\%) & Min & Max & Value & Dist.(\%) & Min & $\operatorname{Max}$ & Value & Dist.(\%) & Min & $\operatorname{Max}$ & Value & Dist.(\%) & Min & Max \\
\hline \multicolumn{17}{|c|}{ Region 1 - Flexible task duration } \\
\hline $\bar{m}_{c}=2$ & 6.1 & 0.7 & 0.0 & 866.1 & 28.9 & 9.9 & 0.0 & 291.3 & 135.2 & 12.5 & 0.0 & 1075.9 & 73.5 & 20.9 & 0.0 & 350.6 \\
\hline $\bar{m}_{c}=3$ & 5.1 & 0.6 & 0.0 & 866.1 & 15.7 & 5.3 & 0.0 & 291.3 & 95.1 & 8.8 & 0.0 & 1075.9 & 58.7 & 16.6 & 0.0 & 350.6 \\
\hline $\bar{m}_{c}=4$ & 4.6 & 0.6 & 0.0 & 866.1 & 7.9 & 2.7 & 0.0 & 291.3 & 69.2 & 6.4 & 0.0 & 1075.9 & 47.9 & 13.6 & 0.0 & 350.6 \\
\hline $\bar{m}_{c}=5$ & 4.4 & 0.5 & 0.0 & 866.1 & 4.3 & 1.5 & 0.0 & 291.3 & 46.8 & 4.3 & 0.0 & 1075.9 & 38.7 & 11.0 & 0.0 & 350.6 \\
\hline $\bar{m}_{c}=6$ & 4.5 & 0.5 & 0.0 & 866.1 & 2.5 & 0.8 & 0.0 & 291.3 & 33.1 & 3.1 & 0.0 & 1075.9 & 32.6 & 9.2 & 0.0 & 350.6 \\
\hline Average & 4.9 & 0.6 & 0.0 & 866.1 & 11.9 & 4.0 & 0.0 & 291.3 & 75.9 & 7.0 & 0.0 & 1075.9 & 50.3 & 14.3 & 0.0 & 350.6 \\
\hline \multicolumn{17}{|c|}{ Region 1 - Fixed task duration } \\
\hline $\bar{m}_{c}=2$ & 10.3 & 1.2 & 0.0 & 866.1 & 59.6 & 20.3 & 0.0 & 291.3 & 156.8 & 14.6 & 0.0 & 1075.9 & 112.2 & 31.9 & 0.0 & 350.6 \\
\hline $\bar{m}_{c}=3$ & 8.8 & 1.0 & 0.0 & 866.1 & 50.8 & 17.3 & 0.0 & 291.3 & 128.2 & 11.9 & 0.0 & 1075.9 & 104.0 & 29.5 & 0.0 & 350.6 \\
\hline $\bar{m}_{c}=4$ & 8.6 & 1.0 & 0.0 & 866.1 & 48.3 & 16.5 & 0.0 & 291.3 & 122.1 & 11.3 & 0.0 & 1075.9 & 103.1 & 29.3 & 0.0 & 350.6 \\
\hline $\bar{m}_{c}=5$ & 8.6 & 1.0 & 0.0 & 866.1 & 47.0 & 16.0 & 0.0 & 291.3 & 118.6 & 11.0 & 0.0 & 1075.9 & 102.8 & 29.2 & 0.0 & 350.6 \\
\hline $\bar{m}_{c}=6$ & 8.5 & 1.0 & 0.0 & 866.1 & 46.6 & 15.9 & 0.0 & 291.3 & 118.5 & 11.0 & 0.0 & 1075.9 & 102.7 & 29.1 & 0.0 & 350.6 \\
\hline Average & 9.0 & 1.0 & 0.0 & 866.1 & 50.5 & 17.2 & 0.0 & 291.3 & 128.8 & 12.0 & 0.0 & 1075.9 & 105.0 & 29.8 & 0.0 & 350.6 \\
\hline \multicolumn{17}{|c|}{ Region 2 - Flexible task duration } \\
\hline $\bar{m}_{c}=2$ & 4.1 & 1.2 & 0.0 & 345.6 & 60.7 & 20.9 & 0.0 & 283.6 & 48.4 & 11.7 & 0.0 & 411.9 & 95.5 & 28.5 & 0.0 & 328.6 \\
\hline $\bar{m}_{c}=3$ & 1.4 & 0.4 & 0.0 & 345.6 & 38.4 & 13.2 & 0.0 & 283.6 & 25.0 & 6.0 & 0.0 & 411.9 & 64.7 & 19.2 & 0.0 & 328.6 \\
\hline $\bar{m}_{c}=4$ & 0.9 & 0.3 & 0.0 & 345.6 & 33.0 & 11.4 & 0.0 & 283.6 & 18.1 & 4.4 & 0.0 & 411 & 56.5 & 16.8 & 0.0 & 328.6 \\
\hline $\begin{array}{l}\bar{m}_{c}=5 \\
m_{c}\end{array}$ & 0.8 & 0.2 & 0.0 & 345.6 & 28.1 & 9.7 & 0.0 & 283.6 & 15.0 & 3.6 & 0.0 & 411.9 & 50.0 & 14.9 & 0.0 & 328.6 \\
\hline $\bar{m}_{c}=6$ & 0.8 & 0.2 & 0.0 & 345.6 & 25.7 & 8.9 & 0.0 & 283.6 & 13.3 & 3.2 & 0.0 & 411.9 & 46.4 & 13.8 & 0.0 & 328.6 \\
\hline Average & 1.6 & 0.5 & 0.0 & 345.6 & 37.2 & 12.8 & 0.0 & 283.6 & 24.0 & 5.8 & 0.0 & 411.9 & 62.6 & 18.6 & 0.0 & 328.6 \\
\hline \multicolumn{17}{|c|}{ Region 2 - Fixed task duration } \\
\hline $\bar{m}_{c}=2$ & 4.6 & 1.3 & 0.0 & 345.6 & 67.0 & 23.1 & 0.0 & 283.6 & 51.3 & 12.4 & 0.0 & 411.9 & 103.7 & 31.0 & 0.0 & 328.6 \\
\hline $\bar{m}_{c}=3$ & 2.1 & 0.6 & 0.0 & 345.6 & 46.8 & 16.1 & 0.0 & 283.6 & 30.4 & 7.3 & 0.0 & 411.9 & 77.1 & 22.9 & 0.0 & 328.6 \\
\hline $\bar{m}_{c}=4$ & 1.7 & 0.5 & 0.0 & 345.6 & 44.6 & 15.4 & 0.0 & 283.6 & 27.2 & 6.6 & 0.0 & 411.9 & 74.8 & 22.3 & 0.0 & 328.6 \\
\hline $\bar{m}_{c}=5$ & 1.7 & 0.5 & 0.0 & 345.6 & 43.3 & 14.9 & 0.0 & 283.6 & 26.5 & 6.4 & 0.0 & 411.9 & 73.7 & 21.9 & 0.0 & 328.6 \\
\hline $\bar{m}_{c}=6$ & 1.6 & 0.5 & 0.0 & 345.6 & 42.5 & 14.6 & 0.0 & 283.6 & 26.5 & 6.4 & 0.0 & 411.9 & 73.2 & 21.8 & 0.0 & 328.6 \\
\hline Average & 2.3 & 0.7 & 0.0 & 345.6 & $\begin{array}{ll}48.8 \\
\end{array}$ & 16.8 & 0.0 & 283.6 & 32.4 & 7.8 & 0.0 & 411.9 & 80.5 & 24.0 & 0.0 & 328.6 \\
\hline
\end{tabular}

Table 4: Computational results for disaggregated instances. MNH/MNL: deviation from minimum frequency for high/low priority tasks, PFH/PFL: deviation from preferred frequency for high/low priority tasks.

(SPD), preference costs (PRF) and caregiver idle time. Caregiver idle time is introduced to measure idle time within a caregiver's working time window. It is important to mention that caregiver idle time does not include their breaks given that such events are legally and contractually required. Directly comparing levels 1-4, as defined in Section 3.1.4, would be incorrect given that the number of tasks in aggregated and disaggregated instances cannot be interpreted in the same manner. The absolute values (Total) and relative improvement (Improv.) in caregiver idle time are shown instead. Deviation from the preferred task duration is not shown as task durations are fixed to $p_{t}^{+}, \forall t \in T$ for this experiment.

Results clearly demonstrate the reduction of caregiver idle time when scheduling with disaggregated tasks. The significant difference in improvement between Region $1(88.7 \%)$ and Region 2 (36.3\%) is due to the number of tasks per client. Each client has, on average, nine tasks in Region 1, while in Region 2 there are only four tasks per client. Results indicate that greater improvements are obtained when specifying the precise breakdown of longer tasks into their constituent shorter tasks. This is somewhat intuitive since having more tasks gives the algorithm greater freedom insofar as leaving low-priority tasks unassigned in favor of assigning those with more importance.

The travel time in both regions increases when scheduling with disaggregated 


\begin{tabular}{|c|c|c|c|c|c|c|c|c|}
\hline \multirow{2}{*}{\multicolumn{2}{|c|}{ Instance }} & \multirow{3}{*}{$\frac{\text { Agg? }}{\text { Yes }}$} & \multicolumn{2}{|c|}{ Caregiver idle time } & \multirow[b]{2}{*}{ CVT } & \multirow[b]{2}{*}{$\mathrm{TT}$} & \multirow[b]{2}{*}{ SPD } & \multirow[b]{2}{*}{$\mathrm{PRF}$} \\
\hline & & & Total & Improv. & & & & \\
\hline Region 1 & Week 1 & & $103 \mathrm{~h} 29 \mathrm{~m}$ & & Oh $00 \mathrm{~m}$ & $13 \mathrm{~h} \mathrm{41m}$ & 0.7 & 38.7 \\
\hline Region 1 & Week 1 & No & $11 \mathrm{~h} 46 \mathrm{~m}$ & $88.6 \%$ & $0 \mathrm{~h} 44 \mathrm{~m}$ & $27 \mathrm{~h} 05 \mathrm{~m}$ & 0.4 & 37.7 \\
\hline Region 1 & Week 2 & Yes & $117 \mathrm{~h} 50 \mathrm{~m}$ & & 0h $00 \mathrm{~m}$ & $15 \mathrm{~h} 29 \mathrm{~m}$ & 0.7 & 36.7 \\
\hline Region 1 & Week 2 & No & $12 \mathrm{~h} 56 \mathrm{~m}$ & $89.0 \%$ & 1h $07 \mathrm{~m}$ & $29 \mathrm{~h} 00 \mathrm{~m}$ & 0.4 & 37.2 \\
\hline Region 1 & Week 3 & Yes & $93 \mathrm{~h} 50 \mathrm{~m}$ & & $0 \mathrm{~h} 00 \mathrm{~m}$ & $12 \mathrm{~h} 43 \mathrm{~m}$ & 0.7 & 39.1 \\
\hline Region 1 & Week 3 & No & $11 \mathrm{~h} 01 \mathrm{~m}$ & $88.3 \%$ & oh $38 \mathrm{~m}$ & $25 \mathrm{~h} 05 \mathrm{~m}$ & 0.3 & 38.2 \\
\hline Region 1 & Week 4 & Yes & $110 \mathrm{~h} 47 \mathrm{~m}$ & & $0 \mathrm{~h} 00 \mathrm{~m}$ & $15 \mathrm{~h} 52 \mathrm{~m}$ & 0.7 & 38.2 \\
\hline Region 1 & Week 4 & No & $13 \mathrm{~h} 45 \mathrm{~m}$ & $87.6 \%$ & 1h $13 \mathrm{~m}$ & $29 \mathrm{~h} 07 \mathrm{~m}$ & 0.4 & 37.3 \\
\hline Region 1 & Week 5 & Yes & $104 \mathrm{~h} 50 \mathrm{~m}$ & & $0 \mathrm{~h} 00 \mathrm{~m}$ & $14 \mathrm{~h} 28 \mathrm{~m}$ & 0.7 & 37.9 \\
\hline Region 1 & Week 5 & No & $12 \mathrm{~h} 09 \mathrm{~m}$ & $88.4 \%$ & oh $52 \mathrm{~m}$ & $26 \mathrm{~h} 21 \mathrm{~m}$ & 0.4 & 37.5 \\
\hline Region 1 & Week 6 & Yes & $96 \mathrm{~h} 45 \mathrm{~m}$ & & $0 \mathrm{~h} 00 \mathrm{~m}$ & $8 \mathrm{~h} 58 \mathrm{~m}$ & 0.8 & 37.3 \\
\hline Region 1 & Week 6 & No & $9 \mathrm{~h} 14 \mathrm{~m}$ & $90.5 \%$ & $0 \mathrm{~h} 34 \mathrm{~m}$ & $22 \mathrm{~h} 58 \mathrm{~m}$ & 0.4 & 37.3 \\
\hline Region 1 & Week 7 & Yes & $104 \mathrm{~h} 42 \mathrm{~m}$ & & $0 \mathrm{~h} 00 \mathrm{~m}$ & $12 \mathrm{~h} 57 \mathrm{~m}$ & 0.7 & 39.2 \\
\hline Region 1 & Week 7 & No & $11 \mathrm{~h} 54 \mathrm{~m}$ & $88.6 \%$ & oh 39m & $25 \mathrm{~h} 14 \mathrm{~m}$ & 0.3 & 38.5 \\
\hline Region 1 & Week 8 & Yes & $103 \mathrm{~h} 47 \mathrm{~m}$ & & $0 \mathrm{~h} 00 \mathrm{~m}$ & $11 \mathrm{~h} 29 \mathrm{~m}$ & 0.7 & 38.6 \\
\hline Region 1 & Week 8 & No & $10 \mathrm{~h} 37 \mathrm{~m}$ & $89.8 \%$ & 0h $30 \mathrm{~m}$ & $25 \mathrm{~h} 18 \mathrm{~m}$ & 0.4 & 37.9 \\
\hline Region 1 & Week 9 & Yes & $101 \mathrm{~h} 01 \mathrm{~m}$ & & $0 \mathrm{~h} 00 \mathrm{~m}$ & $10 \mathrm{~h} 02 \mathrm{~m}$ & 0.7 & 38.1 \\
\hline Region 1 & Week 9 & No & 11h 49m & $88.3 \%$ & 0h $17 \mathrm{~m}$ & $23 \mathrm{~h} 26 \mathrm{~m}$ & 0.4 & 38.2 \\
\hline Region 1 & Week 10 & Yes & $113 \mathrm{~h} 02 \mathrm{~m}$ & & oh $00 \mathrm{~m}$ & $18 \mathrm{~h} 07 \mathrm{~m}$ & 0.7 & 50.0 \\
\hline Region 1 & Week 10 & No & $13 \mathrm{~h} 18 \mathrm{~m}$ & $88.2 \%$ & $1 \mathrm{~h} 49 \mathrm{~m}$ & $29 \mathrm{~h} 29 \mathrm{~m}$ & 0.4 & 50.0 \\
\hline \multirow[t]{2}{*}{ Region 1} & Average & Yes & $105 \mathrm{~h} 00 \mathrm{~m}$ & & oh 00m & $13 \mathrm{~h} 23 \mathrm{~m}$ & 0.7 & 39.4 \\
\hline & & No & $11 \mathrm{~h} 51 \mathrm{~m}$ & $88.7 \%$ & $0 \mathrm{~h} 50 \mathrm{~m}$ & $26 \mathrm{~h} 18 \mathrm{~m}$ & 0.4 & 39.0 \\
\hline Region 2 & Week 1 & Yes & $88 \mathrm{~h} 48 \mathrm{~m}$ & & oh $00 \mathrm{~m}$ & $13 \mathrm{~h} 60 \mathrm{~m}$ & 0.8 & 37.4 \\
\hline Region 2 & Week 1 & No & $52 \mathrm{~h} 47 \mathrm{~m}$ & $40.6 \%$ & 0h 35m & $14 \mathrm{~h} 09 \mathrm{~m}$ & 0.3 & 34.9 \\
\hline Region 2 & Week 2 & Yes & $70 \mathrm{~h} 53 \mathrm{~m}$ & & $0 \mathrm{~h} 00 \mathrm{~m}$ & $13 \mathrm{~h} 09 \mathrm{~m}$ & 0.8 & 37.6 \\
\hline Region 2 & Week 2 & No & $37 \mathrm{~h} 59 \mathrm{~m}$ & $46.4 \%$ & Oh $57 \mathrm{~m}$ & $13 \mathrm{~h} 50 \mathrm{~m}$ & 0.3 & 37.1 \\
\hline Region 2 & Week 3 & Yes & $95 \mathrm{~h} 03 \mathrm{~m}$ & & Oh $00 \mathrm{~m}$ & $13 \mathrm{~h} 47 \mathrm{~m}$ & 0.8 & 36.2 \\
\hline Region 2 & Week 3 & No & $61 \mathrm{~h} 45 \mathrm{~m}$ & $35.0 \%$ & $0 \mathrm{~h} 46 \mathrm{~m}$ & $14 \mathrm{~h} 28 \mathrm{~m}$ & 0.4 & 35.4 \\
\hline Region 2 & Week 4 & Yes & $70 \mathrm{~h} 53 \mathrm{~m}$ & & $0 \mathrm{~h} 00 \mathrm{~m}$ & $11 \mathrm{~h} 48 \mathrm{~m}$ & 0.8 & 39.0 \\
\hline Region 2 & Week 4 & No & $43 \mathrm{~h} 55 \mathrm{~m}$ & $38.0 \%$ & 0h $33 \mathrm{~m}$ & $12 \mathrm{~h} 10 \mathrm{~m}$ & 0.3 & 36.1 \\
\hline Region 2 & Week 5 & Yes & $66 \mathrm{~h} 27 \mathrm{~m}$ & & 0h $00 \mathrm{~m}$ & $12 \mathrm{~h} 30 \mathrm{~m}$ & 0.9 & 37.8 \\
\hline Region 2 & Week 5 & No & $47 \mathrm{~h} 33 \mathrm{~m}$ & $28.5 \%$ & oh $34 \mathrm{~m}$ & $12 \mathrm{~h} 36 \mathrm{~m}$ & 0.3 & 35.5 \\
\hline Region 2 & Week 6 & Yes & $25 \mathrm{~h} 47 \mathrm{~m}$ & & $0 \mathrm{~h} 00 \mathrm{~m}$ & $5 \mathrm{~h} 32 \mathrm{~m}$ & 0.8 & 38.0 \\
\hline Region 2 & Week 6 & No & $19 \mathrm{~h} 22 \mathrm{~m}$ & $24.9 \%$ & $0 \mathrm{~h} 11 \mathrm{~m}$ & $6 \mathrm{~h} 16 \mathrm{~m}$ & 0.3 & 34.4 \\
\hline Region 2 & Week 7 & Yes & $56 \mathrm{~h} 20 \mathrm{~m}$ & & $0 \mathrm{~h} 00 \mathrm{~m}$ & $8 \mathrm{~h} 16 \mathrm{~m}$ & 0.8 & 39.1 \\
\hline Region 2 & Week 7 & No & $39 \mathrm{~h} 32 \mathrm{~m}$ & $29.8 \%$ & 0h $38 \mathrm{~m}$ & $9 \mathrm{~h} 03 \mathrm{~m}$ & 0.3 & 35.2 \\
\hline Region 2 & Week 8 & Yes & $62 \mathrm{~h} 52 \mathrm{~m}$ & & $0 \mathrm{~h} 00 \mathrm{~m}$ & $10 \mathrm{~h} 36 \mathrm{~m}$ & 0.7 & 36.6 \\
\hline Region 2 & Week 8 & No & $36 \mathrm{~h} 57 \mathrm{~m}$ & $41.2 \%$ & oh $58 \mathrm{~m}$ & $11 \mathrm{~h} 52 \mathrm{~m}$ & 0.3 & 36.5 \\
\hline Region 2 & Week 9 & Yes & $72 \mathrm{~h} 28 \mathrm{~m}$ & & $0 \mathrm{~h} 00 \mathrm{~m}$ & $10 \mathrm{~h} 20 \mathrm{~m}$ & 0.7 & 36.7 \\
\hline Region 2 & Week 9 & No & $41 \mathrm{~h} 49 \mathrm{~m}$ & $42.3 \%$ & $0 \mathrm{~h} 52 \mathrm{~m}$ & $11 \mathrm{~h} 12 \mathrm{~m}$ & 0.3 & 35.5 \\
\hline Region 2 & Week 10 & Yes & $60 \mathrm{~h} 51 \mathrm{~m}$ & & $0 \mathrm{~h} 00 \mathrm{~m}$ & $8 \mathrm{~h} 45 \mathrm{~m}$ & 0.7 & 37.3 \\
\hline Region 2 & Week 10 & No & $38 \mathrm{~h} 38 \mathrm{~m}$ & $36.5 \%$ & 0h $39 \mathrm{~m}$ & $9 \mathrm{~h} 20 \mathrm{~m}$ & 0.3 & 36.0 \\
\hline \multirow[t]{2}{*}{ Region 2} & Average & Yes & $67 \mathrm{~h} 02 \mathrm{~m}$ & & Oh $00 \mathrm{~m}$ & $10 \mathrm{~h} 52 \mathrm{~m}$ & 0.8 & 37.6 \\
\hline & & No & $42 \mathrm{~h} 01 \mathrm{~m}$ & $36.3 \%$ & $0 \mathrm{~h} 40 \mathrm{~m}$ & 11h $30 \mathrm{~m}$ & 0.3 & 35.7 \\
\hline
\end{tabular}

Table 5: A comparison of scheduling with aggregated and disaggregated tasks with fixed task duration and a maximum of two client visits per caregiver per day. CVT: deviation from the minimum client visit time, TT: travel time, SPD: spreading cost, PRF: preference costs. 
tasks. However, the fraction of time spent traveling remains relatively small: there is an increase from $2.3 \%$ to $4.7 \%$ for Region 1, and a negligible increase from $2.1 \%$ to $2.2 \%$ for Region 2 . These relatively small increases represent the payoff for greatly reducing the amount of caregiver idle time from $18.7 \%$ to $2.1 \%$ in Region 1 , and from $12.8 \%$ to $8.2 \%$ in Region 2. The changes in PRF and CVT are also negligible. SPD have generally reduced from 0.7 to 0.4 for Region 1 and from 0.8 to 0.3 for Region 2 on average.

Providing disaggregated task information may significantly impede an organization's administrative process. However, disaggregating tasks has a significantly positive impact on scheduling particularly when a region is understaffed. These results demonstrate how big blocks of tasks should be avoided if one wishes to maximize the amount of scheduled care.

\subsection{Impact of flexible task duration}

This section analyzes the impact of flexible task duration when scheduling with aggregated tasks and allowing each caregiver to visit at most three clients per day. Two algorithmic configurations were analyzed for each problem instance: one including, and another excluding, the change duration neighborhood. Table 6 presents the number of unassigned tasks for different priority and requirement levels $(\mathrm{MNH}$, MNL, PFH, PFL), deviation from minimum client visit time (CVT), deviation from the preferred task duration (DUR), total travel time (TT), spreading costs (SPD), preference costs $(\mathrm{PRF})$ and caregiver idle time. Reported values are the average of ten runs.

Significant reductions in the number of caregiver idle time occur in Region 1 (66.9\%). However, Region $2(17.1 \%)$ did not improve quite as much and this can be explained by the flexibility permitted. It is interesting to note, as shown in Table 2 , for week 1 of Region 1 that on average tasks' durations are reduced from $34 \mathrm{~m}$ to $19 \mathrm{~m}$ which is $44 \%$ less. However, for week 1 of Region 2, on average task durations are reduced from $52 \mathrm{~m}$ to $45 \mathrm{~m}$ which is only $13 \%$ less. The fact that blocks in Region 2 remain longer than those in Region 1 helps clarify why the improvement is less dramatic, albeit still significant. There is a reduction of the number of unassigned tasks for all priority and requirement levels. This comes, however, at the expense of an increase in preferred task duration deviation, indicating that high priority tasks may be scheduled more frequently but for shorter durations. This phenomenon is most evident in Region 1, which suffered from understaffing. Overall, the total caregiver idle time still decreases, which indicates that, in general, more care is provided by the available caregivers.

The impact on the deviation from minimum consecutive client time, spreading 


\begin{tabular}{|c|c|c|c|c|c|c|c|c|c|c|c|c|c|}
\hline & & \multirow[b]{2}{*}{ Flex? } & \multicolumn{2}{|c|}{ Caregiver idle time } & \multicolumn{4}{|c|}{ Number of unassigned tasks } & \multirow[b]{2}{*}{ CVT } & \multirow[b]{2}{*}{ DUR } & \multirow[b]{2}{*}{$\mathrm{TT}$} & \multirow[b]{2}{*}{ SPD } & \multirow[b]{2}{*}{ PRF } \\
\hline \multicolumn{2}{|c|}{ Instance } & & Total & Improv. & $\mathrm{MNH}$ & MNL & $\mathrm{PFH}$ & PFL & & & & & \\
\hline Region 1 & Week 1 & No & $77 \mathrm{~h} 12 \mathrm{~m}$ & & 41.8 & 0.0 & 81.3 & 0.0 & oh $00 \mathrm{~m}$ & oh $00 \mathrm{~m}$ & $15 \mathrm{~h} 17 \mathrm{~m}$ & 0.7 & 38.0 \\
\hline Region 1 & Week 1 & Yes & $21 \mathrm{~h} 28 \mathrm{~m}$ & $72.2 \%$ & 2.2 & 0.0 & 18.2 & 0.0 & $0 \mathrm{~h} 00 \mathrm{~m}$ & $209 \mathrm{~h} 30 \mathrm{~m}$ & $24 \mathrm{~h} 08 \mathrm{~m}$ & 0.8 & 38.7 \\
\hline Region 1 & Week 2 & No & $89 \mathrm{~h} 48 \mathrm{~m}$ & & 36.6 & 0.0 & 75.8 & 0.0 & $0 \mathrm{~h} 00 \mathrm{~m}$ & oh $00 \mathrm{~m}$ & $16 \mathrm{~h} 56 \mathrm{~m}$ & 0.7 & 37.8 \\
\hline Region 1 & Week 2 & Yes & $28 \mathrm{~h} 56 \mathrm{~m}$ & $67.8 \%$ & 2.0 & 0.0 & 14.9 & 0.0 & $0 \mathrm{~h} 00 \mathrm{~m}$ & $196 \mathrm{~h} 15 \mathrm{~m}$ & $25 \mathrm{~h} 32 \mathrm{~m}$ & 0.8 & 37.8 \\
\hline Region 1 & Week 3 & No & $71 \mathrm{~h} 13 \mathrm{~m}$ & & 47.8 & 0.0 & 88.1 & 0.0 & $0 \mathrm{~h} 00 \mathrm{~m}$ & Oh $00 \mathrm{~m}$ & $14 \mathrm{~h} 46 \mathrm{~m}$ & 0.7 & 39.6 \\
\hline Region 1 & Week 3 & Yes & $19 \mathrm{~h} 09 \mathrm{~m}$ & $73.1 \%$ & 2.4 & 0.0 & 27.0 & 0.0 & $0 \mathrm{~h} 00 \mathrm{~m}$ & $211 \mathrm{~h} 22 \mathrm{~m}$ & $22 \mathrm{~h} 27 \mathrm{~m}$ & 0.8 & 38.6 \\
\hline Region 1 & Week 4 & No & $84 \mathrm{~h} 04 \mathrm{~m}$ & & 34.5 & 0.0 & 71.7 & 0.0 & $0 \mathrm{~h} 00 \mathrm{~m}$ & oh $00 \mathrm{~m}$ & $16 \mathrm{~h} 44 \mathrm{~m}$ & 0.7 & 38.5 \\
\hline Region 1 & Week 4 & Yes & $32 \mathrm{~h} 49 \mathrm{~m}$ & $61.0 \%$ & 2.0 & 0.0 & 15.8 & 0.0 & $0 \mathrm{~h} 00 \mathrm{~m}$ & $188 \mathrm{~h} 02 \mathrm{~m}$ & $24 \mathrm{~h} 06 \mathrm{~m}$ & 0.8 & 38.1 \\
\hline Region 1 & Week 5 & No & $79 \mathrm{~h} 21 \mathrm{~m}$ & & 39.8 & 0.4 & 81.0 & 0.4 & Oh $00 \mathrm{~m}$ & oh $00 \mathrm{~m}$ & $15 \mathrm{~h} 35 \mathrm{~m}$ & 0.7 & 38.9 \\
\hline Region 1 & Week 5 & Yes & $23 \mathrm{~h} 25 \mathrm{~m}$ & $70.5 \%$ & 2.0 & 0.0 & 21.2 & 0.0 & $0 \mathrm{~h} 00 \mathrm{~m}$ & $204 \mathrm{~h} 28 \mathrm{~m}$ & $23 \mathrm{~h} 31 \mathrm{~m}$ & 0.8 & 38.5 \\
\hline Region 1 & Week 6 & No & $62 \mathrm{~h} 57 \mathrm{~m}$ & & 51.2 & 0.4 & 92.9 & 0.4 & $0 \mathrm{~h} 00 \mathrm{~m}$ & oh $00 \mathrm{~m}$ & $11 \mathrm{~h} 57 \mathrm{~m}$ & 0.8 & 38.1 \\
\hline Region 1 & Week 6 & Yes & $19 \mathrm{~h} 14 \mathrm{~m}$ & $69.4 \%$ & 6.3 & 0.0 & 42.0 & 0.0 & 0h $03 \mathrm{~m}$ & $187 \mathrm{~h} 35 \mathrm{~m}$ & $20 \mathrm{~h} 32 \mathrm{~m}$ & 0.9 & 37.9 \\
\hline Region 1 & Week 7 & No & $75 \mathrm{~h} 34 \mathrm{~m}$ & & 45.9 & 0.0 & 86.5 & 0.0 & Oh $00 \mathrm{~m}$ & oh $00 \mathrm{~m}$ & $14 \mathrm{~h} 47 \mathrm{~m}$ & 0.6 & 39.4 \\
\hline Region 1 & Week 7 & Yes & $18 \mathrm{~h} 08 \mathrm{~m}$ & $76.0 \%$ & 2.3 & 0.0 & 22.1 & 0.0 & $0 \mathrm{~h} 00 \mathrm{~m}$ & $213 \mathrm{~h} 47 \mathrm{~m}$ & $24 \mathrm{~h} 05 \mathrm{~m}$ & 0.8 & 38.5 \\
\hline Region 1 & Week 8 & No & $71 \mathrm{~h} 22 \mathrm{~m}$ & & 45.0 & 0.1 & 85.8 & 0.1 & $0 \mathrm{~h} 00 \mathrm{~m}$ & 0h $00 \mathrm{~m}$ & $13 \mathrm{~h} 49 \mathrm{~m}$ & 0.7 & 39.5 \\
\hline Region 1 & Week 8 & Yes & $20 \mathrm{~h} 02 \mathrm{~m}$ & $71.9 \%$ & 2.5 & 0.0 & 26.9 & 0.0 & $0 \mathrm{~h} 00 \mathrm{~m}$ & $205 \mathrm{~h} 54 \mathrm{~m}$ & $22 \mathrm{~h} 44 \mathrm{~m}$ & 0.8 & 38.3 \\
\hline Region 1 & Week 9 & No & $68 \mathrm{~h} 13 \mathrm{~m}$ & & 50.4 & 0.0 & 91.2 & 0.0 & $0 \mathrm{~h} 00 \mathrm{~m}$ & oh $00 \mathrm{~m}$ & $12 \mathrm{~h} 01 \mathrm{~m}$ & 0.6 & 39.8 \\
\hline Region 1 & Week 9 & Yes & $16 \mathrm{~h} 03 \mathrm{~m}$ & $76.5 \%$ & 4.9 & 0.0 & 25.7 & 0.0 & $0 \mathrm{~h} 00 \mathrm{~m}$ & $214 \mathrm{~h} 15 \mathrm{~m}$ & $21 \mathrm{~h} 11 \mathrm{~m}$ & 0.8 & 39.7 \\
\hline Region 1 & Week 10 & No & $87 \mathrm{~h} 24 \mathrm{~m}$ & & 13.3 & 0.0 & 51.3 & 0.0 & $0 \mathrm{~h} 00 \mathrm{~m}$ & Oh $00 \mathrm{~m}$ & $19 \mathrm{~h} 30 \mathrm{~m}$ & 0.7 & 50.0 \\
\hline Region 1 & Week 10 & Yes & $55 \mathrm{~h} 00 \mathrm{~m}$ & $37.1 \%$ & 0.0 & 0.0 & 3.6 & 0.0 & $0 \mathrm{~h} 00 \mathrm{~m}$ & $156 \mathrm{~h} 22 \mathrm{~m}$ & $22 \mathrm{~h} 55 \mathrm{~m}$ & 0.7 & 50.0 \\
\hline \multirow[t]{2}{*}{ Region 1} & Average & No & $76 \mathrm{~h} 43 \mathrm{~m}$ & & 40.6 & 0.1 & 80.6 & 0.1 & $0 \mathrm{~h} 00 \mathrm{~m}$ & oh $00 \mathrm{~m}$ & $15 \mathrm{~h} 08 \mathrm{~m}$ & 0.7 & 40.0 \\
\hline & & Yes & $25 \mathrm{~h} 25 \mathrm{~m}$ & $66.9 \%$ & 2.7 & 0.0 & 21.7 & 0.0 & oh $00 \mathrm{~m}$ & $198 \mathrm{~h} 45 \mathrm{~m}$ & $23 \mathrm{~h} 07 \mathrm{~m}$ & 0.8 & 39.6 \\
\hline Region 2 & Week 1 & No & $34 \mathrm{~h} 59 \mathrm{~m}$ & & 5.1 & 1.4 & 9.8 & & $0 \mathrm{~h} 00 \mathrm{~m}$ & Oh 00m & $14 \mathrm{~h} 11 \mathrm{~m}$ & 0.7 & 36.9 \\
\hline Region 2 & Week 1 & Yes & $31 \mathrm{~h} 12 \mathrm{~m}$ & $10.8 \%$ & 2.0 & 1.9 & 3.9 & 1.9 & $0 \mathrm{~h} 00 \mathrm{~m}$ & $14 \mathrm{~h} 58 \mathrm{~m}$ & $14 \mathrm{~h} 20 \mathrm{~m}$ & 0.8 & 36.6 \\
\hline Region 2 & Week 2 & No & $29 \mathrm{~h} 18 \mathrm{~m}$ & & 6.2 & 22.2 & 20.2 & 22.2 & $0 \mathrm{~h} 00 \mathrm{~m}$ & 0h 00m & $13 \mathrm{~h} 22 \mathrm{~m}$ & 0.8 & 37.4 \\
\hline Region 2 & Week 2 & Yes & $23 \mathrm{~h} 39 \mathrm{~m}$ & $19.3 \%$ & 1.3 & 9.6 & 15.3 & 9.6 & $0 \mathrm{~h} 00 \mathrm{~m}$ & $42 \mathrm{~h} 05 \mathrm{~m}$ & $13 \mathrm{~h} 38 \mathrm{~m}$ & 0.8 & 37.2 \\
\hline Region 2 & Week 3 & No & $47 \mathrm{~h} 57 \mathrm{~m}$ & & 5.4 & 4.0 & 11.4 & 4.0 & $0 \mathrm{~h} 00 \mathrm{~m}$ & oh 00m & $13 \mathrm{~h} 13 \mathrm{~m}$ & 0.7 & 36.2 \\
\hline Region 2 & Week 3 & Yes & $41 \mathrm{~h} 12 \mathrm{~m}$ & $14.1 \%$ & 1.6 & 3.9 & 4.7 & 3.9 & $0 \mathrm{~h} 00 \mathrm{~m}$ & $18 \mathrm{~h} 37 \mathrm{~m}$ & $13 \mathrm{~h} 26 \mathrm{~m}$ & 0.7 & 36.9 \\
\hline Region 2 & Week 4 & No & $18 \mathrm{~h} 42 \mathrm{~m}$ & & 6.9 & 31.3 & 20.9 & 31.3 & $0 \mathrm{~h} 00 \mathrm{~m}$ & 0h 00m & $12 \mathrm{~h} 07 \mathrm{~m}$ & 0.7 & 38.9 \\
\hline Region 2 & Week 4 & Yes & $19 \mathrm{~h} 59 \mathrm{~m}$ & $-6.9 \%$ & 1.6 & 17.3 & 15.6 & 17.3 & $0 \mathrm{~h} 00 \mathrm{~m}$ & $51 \mathrm{~h} 31 \mathrm{~m}$ & $12 \mathrm{~h} 00 \mathrm{~m}$ & 0.8 & 39.5 \\
\hline Region 2 & Week 5 & No & $25 \mathrm{~h} 10 \mathrm{~m}$ & & 7.0 & 11.9 & 21.0 & 11.9 & $0 \mathrm{~h} 00 \mathrm{~m}$ & 0h 00m & $12 \mathrm{~h} 36 \mathrm{~m}$ & 0.7 & 38.4 \\
\hline Region 2 & Week 5 & Yes & $23 \mathrm{~h} 26 \mathrm{~m}$ & $6.9 \%$ & 2.0 & 5.9 & 14.6 & 5.9 & $0 \mathrm{~h} 00 \mathrm{~m}$ & $38 \mathrm{~h} 59 \mathrm{~m}$ & $12 \mathrm{~h} 44 \mathrm{~m}$ & 0.7 & 38.6 \\
\hline Region 2 & Week 6 & No & $14 \mathrm{~h} 17 \mathrm{~m}$ & & 55.3 & 63.5 & 69.3 & 63.5 & $0 \mathrm{~h} 00 \mathrm{~m}$ & oh $00 \mathrm{~m}$ & $5 \mathrm{~h} 23 \mathrm{~m}$ & 0.6 & 38.1 \\
\hline Region 2 & Week 6 & Yes & $5 \mathrm{~h} 54 \mathrm{~m}$ & $58.7 \%$ & 33.9 & 66.6 & 47.9 & 66.6 & $0 \mathrm{~h} 00 \mathrm{~m}$ & $58 \mathrm{~h} 34 \mathrm{~m}$ & $7 \mathrm{~h} 12 \mathrm{~m}$ & 0.8 & 38.8 \\
\hline Region 2 & Week 7 & No & $20 \mathrm{~h} 36 \mathrm{~m}$ & & 21.2 & 51.7 & 35.2 & 51.7 & 0h $00 \mathrm{~m}$ & oh 00m & $8 \mathrm{~h} 29 \mathrm{~m}$ & 0.7 & 38.0 \\
\hline Region 2 & Week 7 & Yes & $16 \mathrm{~h} 23 \mathrm{~m}$ & $20.4 \%$ & 2.3 & 51.2 & 16.3 & 51.2 & $0 \mathrm{~h} 00 \mathrm{~m}$ & $67 \mathrm{~h} 02 \mathrm{~m}$ & $9 \mathrm{~h} 19 \mathrm{~m}$ & 0.9 & 37.5 \\
\hline Region 2 & Week 8 & No & $21 \mathrm{~h} 12 \mathrm{~m}$ & & 8.0 & 33.5 & 22.0 & 33.5 & $0 \mathrm{~h} 00 \mathrm{~m}$ & 0h 00m & $10 \mathrm{~h} 50 \mathrm{~m}$ & 0.7 & 37.5 \\
\hline Region 2 & Week 8 & Yes & $17 \mathrm{~h} 20 \mathrm{~m}$ & $18.2 \%$ & 2.0 & 13.5 & 16.0 & 13.5 & $0 \mathrm{~h} 00 \mathrm{~m}$ & $60 \mathrm{~h} 53 \mathrm{~m}$ & $11 \mathrm{~h} 14 \mathrm{~m}$ & 0.7 & 38.4 \\
\hline Region 2 & Week 9 & No & $23 \mathrm{~h} 06 \mathrm{~m}$ & & 8.2 & 46.0 & 22.2 & 46.0 & $0 \mathrm{~h} 00 \mathrm{~m}$ & oh $00 \mathrm{~m}$ & $10 \mathrm{~h} 51 \mathrm{~m}$ & 0.7 & 37.6 \\
\hline Region 2 & Week 9 & Yes & $18 \mathrm{~h} 12 \mathrm{~m}$ & $21.2 \%$ & 2.0 & 27.2 & 16.0 & 27.2 & $0 \mathrm{~h} 00 \mathrm{~m}$ & $56 \mathrm{~h} 37 \mathrm{~m}$ & $11 \mathrm{~h} 14 \mathrm{~m}$ & 0.8 & 38.0 \\
\hline Region 2 & Week 10 & No & $22 \mathrm{~h} 15 \mathrm{~m}$ & & 11.8 & 53.9 & 25.8 & 53.9 & $0 \mathrm{~h} 00 \mathrm{~m}$ & 0h 00m & $8 \mathrm{~h} 44 \mathrm{~m}$ & 0.7 & 38.2 \\
\hline Region 2 & Week 10 & Yes & $16 \mathrm{~h} 13 \mathrm{~m}$ & $27.1 \%$ & 1.9 & 38.8 & 15.9 & 38.8 & Oh $00 \mathrm{~m}$ & $61 \mathrm{~h} 22 \mathrm{~m}$ & $9 \mathrm{~h} 13 \mathrm{~m}$ & 0.7 & 38.5 \\
\hline \multirow[t]{2}{*}{ Region 2} & Average & No & $25 \mathrm{~h} 45 \mathrm{~m}$ & & 13.5 & 31.9 & 25.8 & 31.9 & oh $00 \mathrm{~m}$ & oh $00 \mathrm{~m}$ & $10 \mathrm{~h} 59 \mathrm{~m}$ & 0.7 & 37.7 \\
\hline & & Yes & $21 \mathrm{~h} 21 \mathrm{~m}$ & $17.1 \%$ & 5.1 & 23.6 & 16.6 & 23.6 & $0 \mathrm{~h} 00 \mathrm{~m}$ & $47 \mathrm{~h} 04 \mathrm{~m}$ & $11 \mathrm{~h} 26 \mathrm{~m}$ & 0.8 & 38.0 \\
\hline
\end{tabular}

Table 6: An assessment of the impact of task duration flexibility. MNH/MNL: deviation from minimum frequency for high/low priority tasks, PFH/PFL: deviation from preferred frequency for high/low priority tasks, CVT: deviation from the minimum client visit time, DUR: deviation from preferred duration, TT: travel time, SPD: spreading cost, PRF: preference costs. 
and preference costs is generally negligible. Travel time does increase in Region 1 from $13 \mathrm{~h} 23 \mathrm{~m}$ to $23 \mathrm{~h} 07 \mathrm{~m}$, which is due to the larger geographic spread of clients in this region.

Whether a region is under- or overstaffed, flexible task duration clearly helps insofar as decreasing caregiver idle time, prioritizing tasks and mitigating the issues associated with scheduling excessively long tasks which inevitably result in job rejection.

\subsection{Impact of maximum number of clients per day}

This section investigates the effect of increasing the maximum number of clients a caregiver may visit per day when scheduling with aggregated tasks and fixed task duration. The maximum number of clients was varied between two and six, with $\bar{m}_{c}=2$ representing current practice in the aforementioned home care organizations. Table 7 reports the objective values in addition to caregiver idle time. Reported values represent the averages over all weeks in each region.

\begin{tabular}{|c|c|c|c|c|c|}
\hline & \multicolumn{5}{|c|}{ Maximum number of clients per day per caregiver $\bar{m}_{c}$} \\
\hline & 2 & 3 & 4 & 5 & 6 \\
\hline \multicolumn{6}{|l|}{ Region 1} \\
\hline Caregiver idle time (total) & $105 \mathrm{~h} 00 \mathrm{~m}$ & $76 \mathrm{~h} \mathrm{43m}$ & $75 \mathrm{~h} 46 \mathrm{~m}$ & $75 \mathrm{~h} 18 \mathrm{~m}$ & $75 \mathrm{~h} 39 \mathrm{~m}$ \\
\hline Caregiver idle time (improv.) & - & $26.9 \%$ & $27.8 \%$ & $28.3 \%$ & $28.0 \%$ \\
\hline Minimum frequency - high priority (MNH) & 45.1 & 40.6 & 40.3 & 40.3 & 40.3 \\
\hline Minimum frequency - low priority (MNL) & 0.4 & 0.1 & 0.1 & 0.1 & 0.1 \\
\hline Preferred frequency - high priority $(\mathrm{PFH})$ & 87.4 & 80.6 & 80.4 & 80.3 & 80.4 \\
\hline Preferred frequency - low priority (PFL) & 0.4 & 0.1 & 0.1 & 0.1 & 0.1 \\
\hline Travel time $(\mathrm{TT})$ & $13 \mathrm{~h} 23 \mathrm{~m}$ & $15 \mathrm{~h} 08 \mathrm{~m}$ & $15 \mathrm{~h} 23 \mathrm{~m}$ & $15 \mathrm{~h} 25 \mathrm{~m}$ & $15 \mathrm{~h} 20 \mathrm{~m}$ \\
\hline Spreading costs (SPD) & 0.7 & 0.7 & 0.7 & 0.7 & 0.7 \\
\hline Preference costs (PRF) & 39.4 & 40.0 & 40.1 & 40.1 & 40.0 \\
\hline \multicolumn{6}{|l|}{ Region 2} \\
\hline Caregiver idle time (total) & $67 \mathrm{~h} 02 \mathrm{~m}$ & $25 \mathrm{~h} 45 \mathrm{~m}$ & $25 \mathrm{~h} 26 \mathrm{~m}$ & $25 \mathrm{~h} 31 \mathrm{~m}$ & $25 \mathrm{~h} 25 \mathrm{~m}$ \\
\hline Caregiver idle time (improv.) & - & $61.6 \%$ & $62.1 \%$ & $61.9 \%$ & $62.1 \%$ \\
\hline Minimum frequency - high priority $(\mathrm{MNH})$ & 15.4 & 13.5 & 13.0 & 13.0 & 13.0 \\
\hline Minimum frequency - low priority (MNL) & 46.5 & 31.9 & 32.7 & 32.8 & 32.8 \\
\hline Preferred frequency - high priority (PFH) & 29.4 & 25.8 & 25.2 & 25.1 & 25.1 \\
\hline Preferred frequency - low priority (PFL) & 46.5 & 31.9 & 32.7 & 32.8 & 32.8 \\
\hline Travel time (TT) & $10 \mathrm{~h} 52 \mathrm{~m}$ & $10 \mathrm{~h} 59 \mathrm{~m}$ & $10 \mathrm{~h} 58 \mathrm{~m}$ & $10 \mathrm{~h} 58 \mathrm{~m}$ & $10 \mathrm{~h} 55 \mathrm{~m}$ \\
\hline Spreading costs (SPD) & 0.8 & 0.7 & 0.7 & 0.7 & 0.7 \\
\hline Preference costs (PRF) & 37.6 & 37.7 & 37.5 & 37.7 & 37.5 \\
\hline
\end{tabular}

Table 7: A comparison of the impact of maximum number of clients per day per caregiver with aggregated tasks and fixed duration.

Region 1 demonstrates a decrease of $26.9 \%$ in caregiver idle time when increasing the number of clients visited per day from two to three. However, for the same region, there is only a $28.0 \%$ improvement when going from two to six clients, indicating 
how improvement stagnates when the maximum number of clients increases beyond $\bar{m}_{c}=3$. Similarly, in Region 2 there is an improvement of $61.6 \%$ with two clients per day but only $62.1 \%$ with six clients per day. Again, this trend is also reflected in the number of unassigned tasks for each priority and requirement level.

Spreading and preference costs are not influenced by increasing the maximum number of clients. Furthermore, while there is an increase in travel time for Region 1 , the fraction of time spent traveling remains small.

As expected, an increase in the maximum number of clients per day has a positive impact on the resulting schedule. However, in the studied cases, the improvement appears to reduce rather quickly and further increasing the number of clients per day may prove either unnecessary or impractical. Two additional tables are presented in Appendix B which consider the impact of disaggregation and duration flexibility when increasing the maximum number of clients per day.

\subsection{Summary}

Table 8 presents the combined impact of all three types of flexibility previously evaluated separately. For each instance and setting, the following values are shown: deviation from the minimum client visit time (CVT), deviation from the preferred task duration (DUR), total travel time (TT), spreading costs (SPD), preference costs (PRF) and caregiver idle time.

Caregiver idle time is reduced by $99.0 \%$ in Region 1 and 93.1\% in Region 2 . Most other objectives remain unaffected under the combined setting, that is, there are only limited changes for travel time, spreading and preference costs. Deviation from preferred duration does increase, however this represents the necessary trade-off associated with decreasing the number of unassigned tasks, as observed in Section 5.4. The increase in deviation from minimum consecutive client time clearly comes at the expense of increasing the number of serviced clients. If caregivers visit more clients per day, the time spent at each client's home necessarily reduces while the number of available caregivers remains the same.

\section{Management policies}

Section 5.6 demonstrated the potential gain when employing the most efficient configuration of the proposed decision support model. However, in practice, it is impossible for an organization to move from its current approach to this highlyflexible setting as the consequences may be far-reaching and its significant strain on caregivers. A gradual approach is required in which the most efficient configuration may be progressively implemented. 


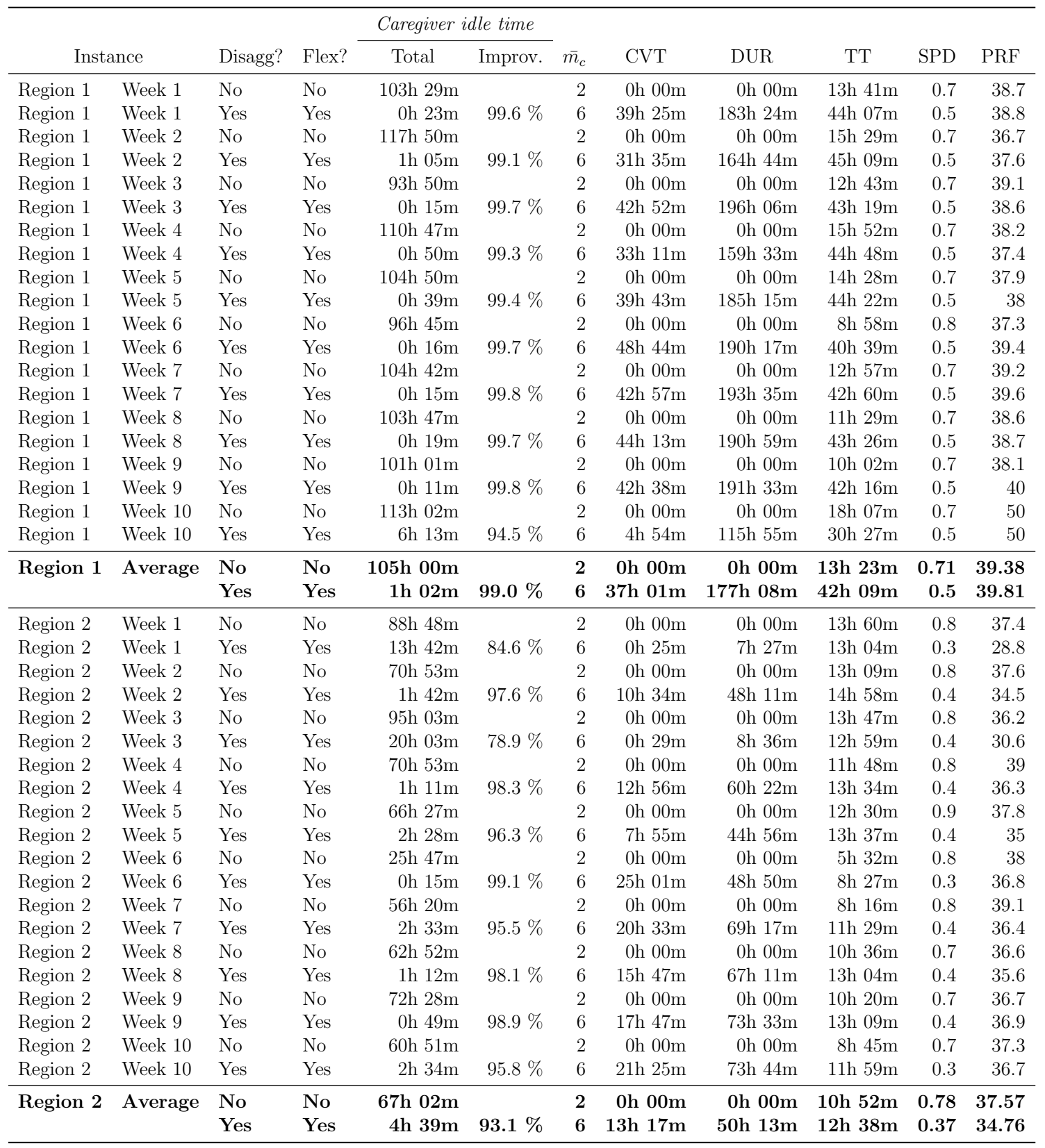

Table 8: Comparing the improvement from worst to best configuration. CVT: deviation from the minimum client visit time, DUR: deviation from preferred duration, TT: travel time, SPD: spreading cost, PRF: preference costs. 
This section proposes four policies which an organization may implement to reapproach its scheduling process. These policies are organized such that they may be implemented sequentially, at each step requiring a greater effort of the organization. These policies gradually introduce changes to the organization which are maintained, thereby introducing greater flexibility with each new policy. Policy 1 increases the maximum number of clients visited per day per caregiver from two to three. Policy 2 introduces flexible task durations on top of Policy 1. Policy 3 further introduces scheduling with disaggregated tasks. Finally, Policy 4 applies all of Policy 3's changes while also increasing the maximum number of clients per day to six. Table 9 quantifies the benefits achievable under these policies, compared against the current practice of scheduling with aggregated tasks, fixed task durations and a maximum of two clients per day per caregiver.

\begin{tabular}{|c|c|c|c|c|c|}
\hline & $\begin{array}{l}\text { Current } \\
\text { practice }\end{array}$ & Policy 1 & Policy 2 & Policy 3 & Policy 4 \\
\hline \multicolumn{6}{|l|}{ Configuration } \\
\hline $\begin{array}{l}\text { Maximum number of clients visited } \\
\text { per day per caregiver }\left(\bar{m}_{c}\right)\end{array}$ & 2 & 3 & 3 & 3 & \\
\hline Flexible task duration & No & No & Yes & Yes & Yes \\
\hline Disaggregated tasks & No & No & No & Yes & Yes \\
\hline \multicolumn{6}{|l|}{ Region 1} \\
\hline Caregiver idle time (total) & $105 \mathrm{~h} 00 \mathrm{~m}$ & $76 \mathrm{~h} \mathrm{43m}$ & $25 \mathrm{~h} 25 \mathrm{~m}$ & $2 \mathrm{~h} 38 \mathrm{~m}$ & $1 \mathrm{~h} 02 \mathrm{~m}$ \\
\hline Caregiver idle time (improv.) & - & $26.9 \%$ & $75.8 \%$ & $97.5 \%$ & $99.0 \%$ \\
\hline Minimum frequency - high priority (MNH) & 45.1 & 40.6 & 2.7 & - & - \\
\hline Minimum frequency - low priority (MNL) & 0.4 & 0.1 & 0.0 & - & - \\
\hline Preferred frequency - high priority $(\mathrm{PFH})$ & 87.4 & 80.6 & 21.7 & - & - \\
\hline Preferred frequency - low priority (PFL) & 0.4 & 0.1 & 0.0 & - & - \\
\hline Minimum client visit time (CVT) & $0 \mathrm{~h} 00 \mathrm{~m}$ & $0 \mathrm{~h} 00 \mathrm{~m}$ & 0h 00m & 7h $31 \mathrm{~m}$ & $37 \mathrm{~h} 01 \mathrm{~m}$ \\
\hline Preferred duration cost (DUR) & $0 \mathrm{~h} 00 \mathrm{~m}$ & $0 \mathrm{~h} 00 \mathrm{~m}$ & $198 \mathrm{~h} 45 \mathrm{~m}$ & $109 \mathrm{~h} 07 \mathrm{~m}$ & $177 \mathrm{~h} 08 \mathrm{~m}$ \\
\hline Travel time $(\mathrm{TT})$ & $13 \mathrm{~h} 23 \mathrm{~m}$ & $15 \mathrm{~h} 08 \mathrm{~m}$ & $23 \mathrm{~h} 07 \mathrm{~m}$ & $32 \mathrm{~h} 26 \mathrm{~m}$ & $42 \mathrm{~h} 09 \mathrm{~m}$ \\
\hline Spreading costs (SPD) & 0.7 & 0.7 & 0.8 & 0.4 & 0.5 \\
\hline Preference costs (PRF) & 39.4 & 40.0 & 39.6 & 39.4 & 39.8 \\
\hline \multicolumn{6}{|l|}{ Region 2} \\
\hline Caregiver idle time (total) & $67 \mathrm{~h} 02 \mathrm{~m}$ & $25 \mathrm{~h} 45 \mathrm{~m}$ & $21 \mathrm{~h} 21 \mathrm{~m}$ & $9 \mathrm{~h} 26 \mathrm{~m}$ & $4 \mathrm{~h} 39 \mathrm{~m}$ \\
\hline Caregiver idle time (improv.) & & $61.6 \%$ & $68.2 \%$ & $85.9 \%$ & $93.1 \%$ \\
\hline Minimum frequency - high priority (MNH) & 15.4 & 13.5 & 5.1 & - & - \\
\hline Minimum frequency - low priority (MNL) & 46.5 & 31.9 & 23.6 & - & - \\
\hline Preferred frequency - high priority (PFH) & 29.4 & 25.8 & 16.6 & - & - \\
\hline Preferred frequency - low priority (PFL) & 46.5 & 31.9 & 23.6 & - & - \\
\hline Minimum client visit time (CVT) & $0 \mathrm{~h} 00 \mathrm{~m}$ & $0 \mathrm{~h} 00 \mathrm{~m}$ & $0 \mathrm{~h} 00 \mathrm{~m}$ & $3 \mathrm{~h} 24 \mathrm{~m}$ & $13 \mathrm{~h} 17 \mathrm{~m}$ \\
\hline Preferred duration cost (DUR) & $0 \mathrm{~h} 00 \mathrm{~m}$ & $0 \mathrm{~h} 00 \mathrm{~m}$ & $47 \mathrm{~h} 04 \mathrm{~m}$ & $24 \mathrm{~h} 12 \mathrm{~m}$ & $50 \mathrm{~h} 13 \mathrm{~m}$ \\
\hline Travel time (TT) & $10 \mathrm{~h} 52 \mathrm{~m}$ & $10 \mathrm{~h} 59 \mathrm{~m}$ & $11 \mathrm{~h} 26 \mathrm{~m}$ & $12 \mathrm{~h} 10 \mathrm{~m}$ & $12 \mathrm{~h} 38 \mathrm{~m}$ \\
\hline Spreading costs (SPD) & 0.8 & 0.7 & 0.8 & 0.3 & 0.4 \\
\hline Preference costs (PRF) & 37.6 & 37.7 & 38.0 & 35.9 & 34.8 \\
\hline
\end{tabular}

Table 9: Comparison of the impact of the different management policies

Under Policy 1, caregiver idle time is reduced by $26.9 \%$ in Region 1 and $61.6 \%$ in Region 2. This is a huge improvement, considering the limited practical effort required to implement this policy. Policy 2 further reduces the caregiver idle time to 
values of $75.8 \%$ and $68.2 \%$ in Region 1 and 2, respectively. Another benefit of this policy is that higher priority tasks may be scheduled, decreasing deviation from the minimum frequency of high priority tasks from 45.1 to 2.7 for Region 1 and from 15.4 to 5.1 for Region 2. While this presents a significant improvement in solution quality, implementing Policy 2 requires organizations to define minimum durations for each of the tasks. Policy 3 almost completely eliminates caregiver idle time while simultaneously presenting the most significant challenge regarding practical implementation since it requires individual task definition. This may prove to be a time-consuming and error-prone process which nevertheless has a significant impact upon schedule quality. Finally, implementing Policy 4 realizes the most efficient model configuration by combining all three types of flexibility. Consequently, caregiver idle time is now close to zero for both regions. In practice, this policy may be difficult for caregivers to accept as it requires them to visit more clients per day, thereby implying shorter visits to each client.

\section{Conclusions and future work}

Scarce resources and increasingly high demand for home care services have placed, and will continue to place, immense pressure on home care organizations. Consequently, decision support tools for organizing available home care workers have become indispensable for ensuring sustainable operations for efficiently delivering required care. Due to the nature of home care activities, new types of flexibility may be exploited which were previously not considered in models for home care scheduling. The present paper identified three such types of flexibility: (i) scheduling with disaggregated tasks, (ii) flexibility in task duration, and (iii) increasing the number of clients visited by a caregiver.

A new rich decision support model based on lexicographic local search which takes into account the aforementioned types of flexibility was introduced. It is important to mention that this model was developed while assuming the presence of understaffed home care organizations and other studies may make their own assumptions. Computational experiments on a new publicly available real-world dataset were analyzed to derive a number of management policies which clearly demonstrated increased scheduling efficiency in the considered regions. The proposed policies were formulated such that they may be gradually implemented, ranging from requiring low implementation effort to an extensive revision of existing workforce management guidelines. The most pervasive of these policies enabled an almost complete elimination of caregiver idle time.

Future research will concern two important directions. Firstly, while rescheduling was not deliberately studied throughout this paper, it plays a key role in the daily op- 
eration of home care organizations. Rescheduling is performed several times per day as clients cancel, require a change in scheduled tasks or caregivers become unavailable due to, for example, illness. Rescheduling is multifaceted in nature: a minimum number of changes is desirable in order to minimally impact all parties involved while still accommodating and providing quality solutions for the new situation. Secondly, human planners schedule small geographic regions in which caregivers and clients live close by, thereby minimizing the number of caregivers and clients to manage simultaneously and reducing the complexity for human planners. However, caregivers may, for example, be required in a different region as a result of lack of staff or the fact that a caregiver and a client may live close to each other but in different regions. Thoughtfully relaxing the concept of regions may consequently result in significant efficiency gains.

Acknowledgment: This research was carried out within the HACES project (Humancentred Automated home CarE Scheduling), realized in collaboration with imec. Project partners are Gezinszorg Villers, Landelijke Thuiszorg, thuiszorg vleminckveld and Tobania, with project support from Agentschap Innoveren \& Ondernemen (Flanders Innovation \& Entrepreneurship). A special thank you also to Jan Christiaens (KU Leuven) for his help with some of the figures. Editorial consultation provided by Luke Connolly (KU Leuven). 


\section{Appendix A Integer linear programming formulation}

This appendix presents an integer linear programming formulation for the considered home care scheduling problem. The indices employed throughout the formulation are:

$$
\begin{aligned}
c & : \text { index for caregivers } \\
t, t^{\prime} & : \text { indices for tasks } \\
k & : \text { index for clients } \\
d & : \text { index for days }
\end{aligned}
$$

The following sets and parameters are considered:

$C$ : set of caregivers

$T$ : set of task types

$K$ : set of clients

$D$ : set of days in the scheduling period

$C_{t}$ : set of caregivers qualified for task $t$

$T_{k}$ : set of tasks associated with client $k$

$T_{0}^{c}$ : set of tasks including dummy tasks 0 and $|T|+1$ of caregiver $c$

$D_{t}$ : set of days on which task type $t$ can be scheduled

$f_{t}^{-}, f_{t}^{+}$: lower and upper bound frequency of task type $t$

$p_{t}^{-}, p_{t}^{+}$: lower and upper bound duration of task type $t$

$h_{t}$ : binary value which is one if and only if task type $t$ is of high priority

$\left[t w_{t d}^{-}, t w_{t d}^{+}\right):$time window of task type $t$ on day $d$

$\left[t w_{c d}^{-}, t w_{c d}^{+}\right)$: time window of caregiver $c$ on day $d$

Three sets of decision variables are defined: 
$x_{t t^{\prime} c d}$ : binary variable which is one if task $t^{\prime}$ is performed directly after task $t$ by caregiver $c$ on day $d$

$s_{t c d}$ : start time of task $t$ by caregiver $c$ on day $d$

$y_{t c d}$ : duration of task $t$ when performed by caregiver $c$ on day $d$

Additionally, three sets of auxiliary decision variables are employed to monitor various penalties:

$z_{t c d}$ : deviation regarding duration of task $t$ by caregiver $c$ on day $d$, which should be greater than or equal to zero

$z_{t}^{-}$: deviation regarding minimum frequency of task $t$, which should be greater than or equal to zero

$z_{t}^{+}$: deviation regarding preferred frequency (upper bound) of task $t$, which should be greater than or equal to zero

The objective function (1) - (4) constitutes a lexicographic ordering of several objectives, which hierarchically determines a solution's quality. As stated in Section 3.1.4, the home care organizations identified the assignment of as many tasks as possible as the single most important objective. Therefore, this model considers the lexicographic ordering which corresponds to (1) deviation from minimum frequency for high priority tasks $(\mathrm{MNH}),(2)$ deviation from minimum frequency for low priority tasks (MNL), (3) deviation from preferred frequency for high priority tasks $(\mathrm{PFH})$ and (4) deviation from preferred frequency for low priority tasks (PFL).

$$
\begin{aligned}
\text { lexmin: level 1: } & \sum_{t \in T} h_{t} z_{t}^{-} \\
\text {level 2: } & \sum_{t \in T}\left(1-h_{t}\right) z_{t}^{-} \\
\text {level 3: } & \sum_{t \in T} h_{t} z_{t}^{+} \\
\text {level 4: } & \sum_{t \in T}\left(1-h_{t}\right) z_{t}^{+}
\end{aligned}
$$

Constraints (5) ensure tasks are only assigned to qualified staff on feasible days. Constraints (6) enforce each task type to be assigned up to its frequency and updates 
penalty variables accordingly. Constraints (7) verify that a task type is assigned at most once per day.

$$
\begin{aligned}
& \begin{array}{l}
x_{t t^{\prime} c d}=0 \\
f_{t}^{-}-z_{t}^{-} \leq \sum_{c \in C} \sum_{t^{\prime} \in T_{0}^{c}} \sum_{d \in D_{t}} x_{t t^{\prime} c d}=f_{t}^{+}-z_{t}^{+}
\end{array} \\
& \sum_{c \in C} \sum_{t^{\prime} \in T_{0}^{c}} x_{t t^{\prime} c d} \leq 1 \\
& \forall t, t^{\prime} \in T, c \in C \backslash C_{t}, d \in D \backslash D_{t^{\prime}} \\
& \forall t \in T \\
& \forall t \in T, d \in D
\end{aligned}
$$

Constraints (8) - (10) ensure the feasibility of caregiver routes through flow conservation constraints. Constraints (8) and (9) ensure that each route begins and ends at the caregiver depot, respectively. Constraints (10) require each caregiver to leave from a location after entering this location. Note that these constraints enable a route to begin and end at the caregiver depot without visiting any intermediate locations.

$$
\begin{array}{lr}
\sum_{t \in T_{0}^{c}} x_{0 t c d}=1 & \forall c \in C, d \in D \\
\sum_{t \in T_{0}^{c}} x_{t(|T|+1) c d}=1 & \forall c \in C, d \in D \\
\sum_{t \in T_{0}^{c}} x_{t t^{\prime} c d}=\sum_{t \in T_{0}^{c}} x_{t^{\prime} t c d} & \forall c \in C, t^{\prime} \in T, d \in D
\end{array}
$$

Constraints (11) set the start time variables associated with scheduled tasks. Constraints (12) and (13) ensure that tasks are scheduled such that they respect task time windows and caregiver availability.

$$
\begin{array}{lr}
s_{t c d}+y_{t c d} \leq s_{t^{\prime} c d}+t w_{t d}^{+}\left(1-x_{t t^{\prime} c d}\right) & \forall c \in C, t, t^{\prime} \in T_{0}^{c}, d \in D \\
t w_{t d}^{-} \sum_{t^{\prime} \in T_{0}^{c}} x_{t t^{\prime} c d} \leq s_{t c d} \leq t w_{t d}^{+} \sum_{t^{\prime} \in T_{0}^{c}} x_{t t^{\prime} c d}-y_{t c d} & \forall c \in C, t \in T, d \in D \\
t w_{c d}^{-} \sum_{t^{\prime} \in T_{0}^{c}} x_{t t^{\prime} c d} \leq s_{t c d} \leq t w_{c d}^{+} \sum_{t^{\prime} \in T_{0}^{c}} x_{t t^{\prime} c d}-y_{t c d} & \forall c \in C, t \in T, d \in D
\end{array}
$$

Constraints (14) and (15) enforce minimum and preferred task durations, and update the penalty variables accordingly. 


$$
\begin{array}{ll}
y_{t c d}+z_{t c d}=p_{t^{\prime}}^{+} \sum_{t^{\prime} \in T_{0}^{c}} x_{t t^{\prime} c d} & \forall c \in C, t \in T, d \in D \\
y_{t c d} \geq p_{t}^{-} \sum_{t^{\prime} \in T_{0}^{c}} x_{t t^{\prime} c d} & \forall c \in C, t \in T, d \in D
\end{array}
$$

Constraints (17) are a set of valid inequalities concerning the duration of scheduled tasks.

$$
\sum_{t \in T} y_{t c d} \leq s_{(|T|+1) c d}-s_{0 c d} \quad \forall c \in C, d \in D
$$

Bounds on the decision variables are imposed by Constraints (18) - (20).

$$
\begin{array}{lr}
x_{t t^{\prime} c d} \in\{0,1\} & \forall t, t^{\prime} \in T, c \in C, d \in D \\
s_{t c d}, y_{t c d}, z_{t c d} \geq 0 & \forall t \in T, c \in C, d \in D \\
z_{t}^{-}, z_{t}^{+} \geq 0 & \forall t \in T
\end{array}
$$




\section{Appendix B Maximum number of clients per day}

This appendix considers the impact of disaggregation (Table 10) and duration flexibility (Table 11) when increasing the maximum number of clients per day. The maximum number of clients was varied between two and six, with $\bar{m}_{c}=2$ representing current practice in the home care organizations. Both tables report the objective values in addition to caregiver idle time. Reported values represent the averages over all weeks in each region.

For Table 10, Region 1 demonstrates a significant decrease of $69.7 \%$ in caregiver idle time when increasing the number of clients visited per day from two to three. Moreover, for the same region, there is a $93.0 \%$ improvement when going from two to six clients, indicating how it further improves when the maximum number of clients increases beyond $\bar{m}_{c}=3$. Similarly, in Region 2 there is an improvement of $77.2 \%$ with two clients per day which rises to $90.9 \%$ when six clients per day are considered. Again, this improvement is also reflected in the number of unassigned tasks for each priority and requirement level.

However, Table 11 illustrates how improvement values stagnate for both regions when the maximum number of clients increases beyond $\bar{m}_{c}=3$. For Region 1 there is an improvement of $66.5 \%$ with two clients per day but only $68.2 \%$ with six clients per day. In Region 2 there is an improvement of $67.8 \%$ with two clients per day but only $68.0 \%$ with six clients per day. These results indicate how increasing the number of clients per caregiver per day beyond two results in little additional improvement. Furthermore, this trend is also reflected in the number of unassigned tasks for each priority and requirement level. 


\begin{tabular}{|c|c|c|c|c|c|}
\hline & \multicolumn{5}{|c|}{ Maximum number of clients per day per caregiver $\bar{m}_{c}$} \\
\hline & 2 & 3 & 4 & 5 & 6 \\
\hline \multicolumn{6}{|l|}{ Region 1} \\
\hline Caregiver idle time (total) & $11 \mathrm{~h} 51 \mathrm{~m}$ & $3 \mathrm{~h} 35 \mathrm{~m}$ & $1 \mathrm{~h} 45 \mathrm{~m}$ & $1 \mathrm{~h} 05 \mathrm{~m}$ & Oh $50 \mathrm{~m}$ \\
\hline Caregiver idle time (improv.) & - & $69.7 \%$ & $85.3 \%$ & $90.9 \%$ & $93.0 \%$ \\
\hline Minimum frequency - high priority (MNH) & 10.3 & 8.8 & 8.6 & 8.6 & 8.5 \\
\hline Minimum frequency - low priority (MNL) & 59.6 & 50.8 & 48.3 & 47.0 & 46.6 \\
\hline Preferred frequency - high priority (PFH) & 156.8 & 128.2 & 122.1 & 118.6 & 118.5 \\
\hline Preferred frequency - low priority (PFL) & 112.2 & 104.0 & 103.1 & 102.8 & 102.7 \\
\hline Minimum client visit time $(\mathrm{CVT})$ & Oh $50 \mathrm{~m}$ & $7 \mathrm{~h} 00 \mathrm{~m}$ & $17 \mathrm{~h} 20 \mathrm{~m}$ & $24 \mathrm{~h} 46 \mathrm{~m}$ & $28 \mathrm{~h} 41 \mathrm{~m}$ \\
\hline Preferred duration cost (DUR) & Oh $00 \mathrm{~m}$ & $0 \mathrm{~h} 00 \mathrm{~m}$ & $0 \mathrm{~h} 00 \mathrm{~m}$ & $0 \mathrm{~h} \mathrm{00m}$ & 0h 00m \\
\hline Travel time (TT) & $26 \mathrm{~h} 18 \mathrm{~m}$ & $31 \mathrm{~h} 08 \mathrm{~m}$ & $35 \mathrm{~h} 31 \mathrm{~m}$ & $38 \mathrm{~h} 05 \mathrm{~m}$ & $39 \mathrm{~h} 34 \mathrm{~m}$ \\
\hline Spreading costs (SPD) & 0.4 & 0.4 & 0.4 & 0.4 & 0.4 \\
\hline Preference costs (PRF) & 39.0 & 39.0 & 39.4 & 39.5 & 39.6 \\
\hline \multicolumn{6}{|l|}{ Region 2} \\
\hline Caregiver idle time (total) & $42 \mathrm{~h} 01 \mathrm{~m}$ & $9 \mathrm{~h} 36 \mathrm{~m}$ & $5 \mathrm{~h} 27 \mathrm{~m}$ & $4 \mathrm{~h} 10 \mathrm{~m}$ & $3 \mathrm{~h} 49 \mathrm{~m}$ \\
\hline Caregiver idle time (improv.) & & $77.2 \%$ & $87.0 \%$ & $90.1 \%$ & $90.9 \%$ \\
\hline Minimum frequency - high priority (MNH) & 4.6 & 2.1 & 1.7 & 1.7 & 1.6 \\
\hline Minimum frequency - low priority (MNL) & 67.0 & 46.8 & 44.6 & 43.3 & 42.5 \\
\hline Preferred frequency - high priority (PFH) & 51.3 & 30.4 & 27.2 & 26.5 & 26.5 \\
\hline Preferred frequency - low priority (PFL) & 103.7 & 77.1 & 74.8 & 73.7 & 73.2 \\
\hline Minimum client visit time (CVT) & $0 \mathrm{~h} 40 \mathrm{~m}$ & $2 \mathrm{~h} 60 \mathrm{~m}$ & $6 \mathrm{~h} 17 \mathrm{~m}$ & $8 \mathrm{~h} 60 \mathrm{~m}$ & $9 \mathrm{~h} 57 \mathrm{~m}$ \\
\hline Preferred duration cost (DUR) & 0h $00 \mathrm{~m}$ & 0h $00 \mathrm{~m}$ & 0h $00 \mathrm{~m}$ & 0h $00 \mathrm{~m}$ & 0h 00m \\
\hline Travel time $(\mathrm{TT})$ & $11 \mathrm{~h} 30 \mathrm{~m}$ & $12 \mathrm{~h} 02 \mathrm{~m}$ & $12 \mathrm{~h} 22 \mathrm{~m}$ & $12 \mathrm{~h} 27 \mathrm{~m}$ & $12 \mathrm{~h} 25 \mathrm{~m}$ \\
\hline Spreading costs (SPD) & 0.3 & 0.3 & 0.3 & 0.3 & 0.3 \\
\hline Preference costs (PRF) & 35.7 & 35.5 & 35.3 & 35.0 & 34.8 \\
\hline
\end{tabular}

Table 10: A comparison of the impact of maximum number of clients per day per caregiver with disaggregated tasks and fixed duration. 


\begin{tabular}{|c|c|c|c|c|c|}
\hline & \multicolumn{5}{|c|}{ Maximum number of clients per day per caregiver $\bar{m}_{c}$} \\
\hline & 2 & 3 & 4 & 5 & 6 \\
\hline \multicolumn{6}{|l|}{ Region 1} \\
\hline Caregiver idle time (total) & $75 \mathrm{~h} 59 \mathrm{~m}$ & $25 \mathrm{~h} 25 \mathrm{~m}$ & $23 \mathrm{~h} 46 \mathrm{~m}$ & $23 \mathrm{~h} 42 \mathrm{~m}$ & $24 \mathrm{~h} 11 \mathrm{~m}$ \\
\hline Caregiver idle time (improv.) & & $66.5 \%$ & $68.7 \%$ & $68.8 \%$ & $68.2 \%$ \\
\hline Minimum frequency - high priority (MNH) & 12.2 & 2.7 & 2.5 & 2.6 & 2.5 \\
\hline Minimum frequency - low priority (MNL) & 0.1 & 0.0 & 0.0 & 0.0 & 0.0 \\
\hline Preferred frequency - high priority (PFH) & 51.0 & 21.7 & 19.1 & 18.9 & 18.8 \\
\hline Preferred frequency - low priority (PFL) & 0.1 & 0.0 & 0.0 & 0.0 & 0.0 \\
\hline Minimum client visit time $(\mathrm{CVT})$ & oh $04 \mathrm{~m}$ & Oh $00 \mathrm{~m}$ & Oh $02 \mathrm{~m}$ & 0h $01 \mathrm{~m}$ & oh $01 \mathrm{~m}$ \\
\hline Preferred duration cost (DUR) & $131 \mathrm{~h} 08 \mathrm{~m}$ & $198 \mathrm{~h} 45 \mathrm{~m}$ & $206 \mathrm{~h} 39 \mathrm{~m}$ & $206 \mathrm{~h} 57 \mathrm{~m}$ & $208 \mathrm{~h} 13 \mathrm{~m}$ \\
\hline Travel time $(\mathrm{TT})$ & $20 \mathrm{~h} 45 \mathrm{~m}$ & $23 \mathrm{~h} 07 \mathrm{~m}$ & $23 \mathrm{~h} 36 \mathrm{~m}$ & $23 \mathrm{~h} 49 \mathrm{~m}$ & $23 \mathrm{~h} 54 \mathrm{~m}$ \\
\hline Spreading costs (SPD) & 0.8 & 0.8 & 0.8 & 0.8 & 0.8 \\
\hline Preference costs (PRF) & 39.4 & 39.6 & 39.9 & 39.7 & 39.8 \\
\hline \multicolumn{6}{|l|}{ Region 2} \\
\hline Caregiver idle time (total) & $66 \mathrm{~h} 13 \mathrm{~m}$ & $21 \mathrm{~h} 21 \mathrm{~m}$ & $20 \mathrm{~h} 21 \mathrm{~m}$ & $20 \mathrm{~h} 46 \mathrm{~m}$ & $21 \mathrm{~h} 13 \mathrm{~m}$ \\
\hline Caregiver idle time (improv.) & & $67.8 \%$ & $69.3 \%$ & $68.6 \%$ & $68.0 \%$ \\
\hline Minimum frequency - high priority (MNH) & 8.1 & 5.1 & 4.7 & 4.6 & 4.4 \\
\hline Minimum frequency - low priority (MNL) & 46.6 & 23.6 & 20.3 & 20.3 & 20.3 \\
\hline Preferred frequency - high priority (PFH) & 22.1 & 16.6 & 16.0 & 15.9 & 15.9 \\
\hline Preferred frequency - low priority (PFL) & 46.6 & 23.6 & 20.3 & 20.3 & 20.3 \\
\hline Minimum client visit time (CVT) & $0 \mathrm{~h} 00 \mathrm{~m}$ & oh $00 \mathrm{~m}$ & $0 \mathrm{~h} 00 \mathrm{~m}$ & oh $00 \mathrm{~m}$ & $0 \mathrm{~h} 00 \mathrm{~m}$ \\
\hline Preferred duration cost (DUR) & $23 \mathrm{~h} 56 \mathrm{~m}$ & $47 \mathrm{~h} 04 \mathrm{~m}$ & $55 \mathrm{~h} 44 \mathrm{~m}$ & $56 \mathrm{~h} 31 \mathrm{~m}$ & $57 \mathrm{~h} 19 \mathrm{~m}$ \\
\hline Travel time $(\mathrm{TT})$ & $11 \mathrm{~h} 12 \mathrm{~m}$ & $11 \mathrm{~h} 26 \mathrm{~m}$ & $11 \mathrm{~h} 27 \mathrm{~m}$ & $11 \mathrm{~h} 27 \mathrm{~m}$ & $11 \mathrm{~h} 26 \mathrm{~m}$ \\
\hline Spreading costs (SPD) & 0.9 & 0.8 & 0.8 & 0.8 & 0.8 \\
\hline Preference costs (PRF) & 37.9 & 38.0 & 37.9 & 38.0 & 38.0 \\
\hline
\end{tabular}

Table 11: A comparison of the impact of maximum number of clients per day per caregiver with aggregated tasks and flexible duration. 
Akjiratikarl, C., Yenradee, P., Drake, P. R., 2007. PSO-based algorithm for home care worker scheduling in the UK. Computers \& Industrial Engineering 53 (4), $559-583$.

Begur, S. V., Miller, D. M., Weaver, J. R., 1997. An integrated spatial DSS for scheduling and routing home-health-care nurses. Interfaces 27 (4), 35-48.

Bertels, S., Fahle, T., 2006. A hybrid setup for a hybrid scenario: Combining heuristics for the home health care problem. Computers \& Operations Research 33 (10), $2866-2890$.

Bredström, D., Rönnqvist, M., 2008. Combined vehicle routing and scheduling with temporal precedence and synchronization constraints. European Journal of Operational Research 191 (1), 19-29.

Castillo-Salazar, J. A., Landa-Silva, D., Qu, R., 2016. Workforce scheduling and routing problems: literature survey and computational study. Annals of Operations Research 239 (1), 39-67.

Di Gaspero, L., Urli, T., 2014. A CP/LNS approach for multi-day homecare scheduling problems. In: Lecture Notes in Computer Science (including subseries Lecture Notes in Artificial Intelligence and Lecture Notes in Bioinformatics). Vol. 8457 LNCS. pp. 1-15.

Dohn, A., Rasmussen, M. S., Justesen, T., Larsen, J., 2008. The Home Care Crew Scheduling Problem. Proceedings of the 1st International Conference on Applied Operational Research, 1-8.

Fikar, C., Hirsch, P., 2016. Home health care routing and scheduling: A review. Computers \& Operations Research 77, 86-95.

Gregory, A., Mackintosh, S., Kumar, S., Grech, C., 2017. Experiences of health care for older people who need support to live at home: A systematic review of the qualitative literature. Geriatric nursing (New York, N.Y.).

Hiermann, G., Prandtstetter, M., Rendl, A., Puchinger, J., Raidl, G. R., 2013. Metaheuristics for solving a multimodal home-healthcare scheduling problem. Central European Journal of Operations Research, 1-25.

Holm, S. G., Angelsen, R. O., 2014. A descriptive retrospective study of time consumption in home care services: how do employees use their working time? BMC Health Services Research 14 (1), 439-449. 
Kolisch, R., 1996. Serial and parallel resource-constrained project scheduling methods revisited: Theory and computation. European Journal of Operational Research $90(2), 320-333$.

Kovacs, A. A., Golden, B. L., Hartl, R. F., Parragh, S. N., 2014. Vehicle routing problems in which consistency considerations are important: A survey. Networks 64 (3), 192-213.

Lanzarone, E., Matta, A., 2014. Robust nurse-to-patient assignment in home care services to minimize overtimes under continuity of care. Operations Research for Health Care 3 (2), 48-58.

Liu, R., Xie, X., Garaix, T., 2014. Hybridization of tabu search with feasible and infeasible local searches for periodic home health care logistics. Omega 47, 17 32 .

Mankowska, D. S., Meisel, F., Bierwirth, C., 2014. The home health care routing and scheduling problem with interdependent services. Health Care Management Science 17 (1), 15-30.

Martinez-Legaz, J. E., 1988. Lexicographical order and duality in multiobjective programming. European Journal of Operational Research 33 (3), 342 - 348.

Maya Duque, P. A., Castro, M., Sörensen, K., Goos, P., 2015. Home care service planning. The case of Landelijke Thuiszorg. European Journal of Operational Research 243 (1), 292-301.

Morito, S., Kishimoto, D., Hayashi, H., Torigoe, A., Okamoto, S., Matsukawa, Y., Taniguchi, N., 2013. A Column Generation Approach to Home Care Staff Routing and Scheduling. In: Operations Research Proceedings. pp. 275-280.

Mutingi, M., Mbohwa, C., 2014. A fuzzy simulated evolution algorithm for multiobjective homecare worker scheduling. IEEE International Conference on Industrial Engineering and Engineering Management 8300 (June), 586-590.

Nickel, S., Schröder, M., Steeg, J., 2012. Mid-term and short-term planning support for home health care services. European Journal of Operational Research 219 (3), $574-587$.

OECD Health Statistics, 2016. Recipients of long-term care in europe. http://dx.doi.org/10.1787/health-data-en. 
Rendl, A., Prandtstetter, M., Hiermann, G., Puchinger, J., Raidl, G., 2012. Hybrid Heuristics for Multimodal Homecare Scheduling. Integration of AI and OR Techniques in Contraint Programming for Combinatorial Optimzation Problems, 339-355.

Research Center Flemish Government, 2015. Flemish region indicators. Tech. rep., Flemish Government.

Shabtay, D., Gaspar, N., Kaspi, M., 2013. A survey on offline scheduling with rejection. Journal of Scheduling 16 (1), 3-28.

Shabtay, D., Steiner, G., 2007. A survey of scheduling with controllable processing times. Discrete Applied Mathematics 155 (13), 1643-1666.

Smet, P., Salassa, F., Vanden Berghe, G., 2017. Local and global constraint consistency in personnel rostering. International Transactions in Operational Research 24 (5), 1099-1117.

Trautsamwieser, A., Hirsch, P., 2011. Optimization of daily scheduling for home health care services. Journal of Applied Operational Research 3 (3), 124-136.

Trautsamwieser, A., Hirsch, P., 2014. A branch-price-and-cut approach for solving the medium-term home health care planning problem. Networks 64 (3), 143-159.

Yang, D.-L., Cheng, T., Yang, S.-J., 2014. Parallel-machine scheduling with controllable processing times and rate-modifying activities to minimise total cost involving total completion time and job compressions. International Journal of Production Research 52 (4), 1133-1141. 